IZA DP No. 6549

Like Father, Like Son?

Intergenerational Education Mobility in India

Mehtabul Azam

Vipul Bhatt

May 2012 


\title{
Like Father, Like Son? Intergenerational Education Mobility in India
}

\author{
Mehtabul Azam \\ World Bank \\ and IZA \\ Vipul Bhatt \\ James Madison University \\ Discussion Paper No. 6549 \\ May 2012 \\ IZA \\ P.O. Box 7240 \\ 53072 Bonn \\ Germany \\ Phone: +49-228-3894-0 \\ Fax: +49-228-3894-180 \\ E-mail: iza@iza.org
}

Any opinions expressed here are those of the author(s) and not those of IZA. Research published in this series may include views on policy, but the institute itself takes no institutional policy positions.

The Institute for the Study of Labor (IZA) in Bonn is a local and virtual international research center and a place of communication between science, politics and business. IZA is an independent nonprofit organization supported by Deutsche Post Foundation. The center is associated with the University of Bonn and offers a stimulating research environment through its international network, workshops and conferences, data service, project support, research visits and doctoral program. IZA engages in (i) original and internationally competitive research in all fields of labor economics, (ii) development of policy concepts, and (iii) dissemination of research results and concepts to the interested public.

IZA Discussion Papers often represent preliminary work and are circulated to encourage discussion. Citation of such a paper should account for its provisional character. A revised version may be available directly from the author. 


\section{ABSTRACT \\ Like Father, Like Son? Intergenerational Education Mobility in India*}

An important constraint in studying intergenerational education mobility for India is the lack of data that contain information about parents' education for the entire adult population. This paper employs a novel strategy to create a unique father-son matched data that is representative of the entire adult male population in India. Using this father-son matched data, we study the extent of intergenerational mobility in educational attainment in India since 1940 s and provide an estimate of how India ranks among other nations. We also document this mobility across social groups, and states in India. Finally, we investigate the evolution of mobility in educational attainment across the two generations and whether this trend differs across social groups and state boundaries. We find that there have been significant improvements in educational mobility across generations in India, at the aggregate level, across social groups, and across states. Although most of the Indian states have made significant progress over time, in terms of improved mobility, there remains significant variation across states with some states faring worse than the others.

JEL Classification: J6, 128

Keywords: intergenerational mobility, educational persistence, India

Corresponding author:

Mehtabul Azam

World Bank

1818 H ST, NW

Mail Stop: H11-1101

Washington, DC 20433

USA

E-mail: mazam1@woldbank.org

\footnotetext{
* The findings, interpretations, and conclusions expressed in this paper are entirely those of the authors. They do not necessarily represent the views of the International Bank for Reconstruction and Development/World Bank and its affiliated organizations, or those of the Executive Directors of the World Bank or the governments they represent.
} 


\section{Introduction}

In most growth episodes across the world, rapid economic growth has also been accompanied by increased inequality in outcomes such as income, wealth, and education. One can argue that such a lopsided rise in fortunes inherently imply inequality in opportunities across groups of people in a society typically identified by gender, race, geographic location, or social class. In such an environment an important channel for inequality stems from intergenerational persistence in economic outcomes. Greater persistence in economic outcomes between generation will exacerbate the inequality problem. In this sense a measure of intergenerational mobility is intrinsically connected to the extent of economic inequality in a society.

India serves as an excellent case study for intergenerational mobility for two reasons. First, historically Indian society has been characterized by a high degree of social stratification governed by the caste system wherein lower castes were typically associated with poor economic outcomes. Although, the caste system has been weakened as a response to various policy measures taken by government, social identity still remains an important dimension of social exclusion and hence gauging how such inertia in economic mobility has changed over time is of interest. Second, although India has experienced rapid economic growth in recent decades, this economic growth has been far from uniformly distributed on regional dimensions. Many large states have experienced below national average economic growth and also have significant differences in terms access to education opportunities (Chaudhuri and Ravallion, 2006; Asadullah and Yalonetzky, 2012). Given the deeply rooted caste system and unequal growth experience of the states in India, understanding the extent of intergen- 
erational mobility and whether there are differential patterns in such mobility across states and social groups is of interest.

Although, as argued above, understanding the extent of intergenerational mobility is especially important for India, this issue has received relatively less attention mainly because lack of suitable data for such kind of studies. As discussed in Section 1.1, most of the existing studies (Jalan and Murgai, 2008; Maitra and Sharma, 2009; Hnatkovskay et al., 2012) rely on the co-residence condition to identify father-son pairs from cross-sectional data. This leads to a significant loss of observations and more importantly raises serious sample selection issue as coresident households may differ systematically from other households. For instance, the identification of parental information achieved through co-residence, will either lead to restricting the analysis to the young adults (Jalan and Murgai, 2008) or giving a cross -sectional estimate based on a sample that is not representative of the adult population (Hnatkovskay et al., 2012). ${ }^{3 / 4}$ In this paper we address this issue by creating a unique father-son matched data, using the nationally representative India Human Development Survey, 2005 (IHDS), that is not limited to coresident households. We believe that our data is more appropriate for studying intergenerational mobility as it is representative of the entire adult male population in India.

In any intergenerational study, the measurement of economic status remains an important issue, and several studies proxy economic status by labor market characteristics such

\footnotetext{
${ }^{3}$ Such limitations are expected if one uses data only for coresident parents to estimate intergenerational mobility because such a condition is more likely to be satisfied for young adults. As a result the estimates of intergenerational elasticities can be severely biased downwards (Franscesconi and Nicoletti, 2006).

${ }^{4}$ In Section 3.1 we discuss, in detail, the issue of co-residence in existing studies on India, the resulting decline in sample size, and the sample selection issue that can arise due to use of co-residence for matching children with parents.
} 
as earnings, occupation, and educational attainment. In this paper, we focus on intergenerational mobility in educational attainment. Although education is not the only proxy for economic status, there are several advantages in using education instead of earnings to measure intergenerational mobility, especially in a developing country context where existence of long panel data is rare. First, on the measurement side, education is less prone to serious errors than earnings. Second, since most individuals complete their education by early or mid twenties, life cycle biases are unlikely to bias estimation when compared with earnings. Finally, there is a vast literature that shows that higher education is associated with higher earnings, better health, and other economic outcomes (see Black and Devereux, 2011), rendering a measure of intergenerational mobility based on education a reasonable proxy for mobility in overall economic status.

This paper attempts to address three important issues in the context of Indian economy. First, what is the extent of intergenerational mobility in educational outcomes in India and how such mobility has changed over time? Second, given deeply rooted divisions along the caste lines, do we see differential patterns for education mobility for different social groups? This will have implications for the gap in economic outcomes between upper and lower castes in India. Finally, do we observe differential mobility patterns across states, with greater mobility in some states matched with lack of such mobility in other states?

The paper contributes to the existing literature in following ways. First, we are able to match about $97 \%$ of the males aged $20-65$ in our sample with their father information. As a result, unlike other studies on India (see Section 3.1), the estimates presented in this 
paper do not suffer from sample selection bias caused by limiting the analysis to coresident households to identify parents' information. Second, following Hertz et al. (2007) methodology closely, we are able to rank India, in terms of intergenerational education mobility, among other nations. To the best of our knowledge, there exists no comparable estimate of intergenerational mobility that can be used to rank India among other countries. Third, we are able to track changes in mobility across birth cohorts going back to as early as 1940s. We provide mobility estimates for successive birth cohorts for at the aggregate level, and by social groups. Finally, the regional dimension of intergenerational education mobility in India remains largely unexplored. In this paper we attemp to fill this void in the literature and provide state-level estimates of intergenerational education mobility by birth cohorts. Hence, using our estimates, we can address the issue of regional variation in intergenerational education mobility as well as the cohort trend in this cross-state variation.

There are several key findings. First, we find that there has been an increase in mobility in educational attainment in India over time. The average intergenerational correlation in education for India is 0.523 which is higher than the average global correlation of 0.42 reported by Hertz et al. (2007). Second, we find that at the lower end of education distribution, sons of less educated fathers are more likely to achieve greater education than their fathers, implying improved mobility. However, at the top end of the distribution there is evidence for regression of sons' educational attainment. Specifically, we find that sons of highly educated fathers are more likely to achieve less education than their father. Third, these patterns in intergenerational education mobility broadly hold across social groups. This implies that 
there has been a decrease in the inertia of the prevalent discrimination based on caste. Finally, using our estimates from the state level analysis, we find that although most states witnessed an increase in education mobility across cohorts, there is significant variation in education mobility across states. For instance states like West Bengal and Tamil Nadu did not experience that much improvement in education mobility when compared to states like Maharashtra, Orissa and Rajasthan. We also find that this regional variation is smaller for more recent cohorts implying greater uniformity across states in terms of education mobility. We provide some evidence that our estimates of mobility at the state level correlate with the state level education spending. Specifically we find a strong positive association between state ranking in terms of per capita education spending and our estimated mobility measure. This correlation although not causal is of policy interest and can be used to initiate policy measures to mitigate state level difference in educational opportunities.

The remainder of the paper is organized as follows. Section 2 presents a brief review of the literature on the intergenerational mobility in educational attainment. Section 3 discusses the data, the approach used to create a father-son matched data for India, and descriptive statistics for the sample used in the study. Section 4 outlines the conceptual framework underlying our empirical analysis. Section 5 presents the estimation results for our regression model. Section 6 provides estimates of mobility across the education distribution using transition matrices. Section 7 provides a discussion of our main findings and their implications for the education policy measures that have been implemented in India postindependence. Section 8 concludes. 


\section{Related Literature}

The issue of intergenerational mobility in income, education, and occupation has been extensively explored in the literature. Black and Devereux (2011) present a recent survey of the evidence and methodological problems of the research available for the developed economies. ${ }^{5}$ Hertz et al. (2007) study the trends in intergenerational transmission of educational for a sample of 42 countries. ${ }^{6}$ They document large regional differences in educational persistence, with Latin America displaying the highest intergenerational correlations, and the Nordic countries the lowest. They estimate the global average correlation between parent and child's schooling to be around 0.42 for the past fifty years. Daude (2011) presents educational mobility estimates for 18 countries in the Latin America region and found relatively low degree of intergenerational social mobility in Latin America.

The issue of intergenerational mobility in India has only recently started attracting attention. ${ }^{7}$ Jalan and Murgai (2008) investigate the educational mobility among the age group 15-19 using 1992-93 and 1998-99 National Family Health Survey (NFHS) data. They found that education mobility for age group 15-19 has increased significantly between 1992-92 and 1999-00, and that education gaps between backward and forward castes are not that large once other attributes are controlled for. An important limitation of their analysis is that,

\footnotetext{
${ }^{5}$ See also Solon (2002) for an earlier survey of the evidence on earning mobility across generations.

${ }^{6}$ Their sample does not include India

${ }^{7}$ Munshi and Rosenzweig (2006) used a survey for 4900 households residing in Bombay and investigate the effect of caste-based labor market networks on occupational mobility. They found that for males there are strong effects of traditional networks on occupational choice. However, for females they found relatively greater mobility in occupational choices. Munshi and Rosenzweig (2009) used a panel data of rural households, 1982 Rural Economic Development Survey, that covered 259 villages in 16 states in India. They report low rates of spatial and marital mobility in rural India, and relate these to the existence of caste networks that provide mutual insurance to their members.
} 
in the NFHS data, respondents are not directly asked about the education of their parents. Hence, parental outcomes are only known for child-parent pairs that are still living in the same household. As a result they only focus on children aged 15-19 years who are more likely to be living with their parents.

Maitra and Sharma (2009) use the India Human Development Survey, 2005 (IHDS) to describe how educational attainments of adult male (20 and above) have changed across cohorts. Using an OLS regression of years of schooling on birth year, they report that the average years of education increased by 1.2 years (by 1 year) each decade for urban females (for rural males and females). However, the average years of schooling increased by about 0.5 years per decade for urban males probably because of higher average years of schooling for urban males to begin with. They also explored the effect of parental education (both father and mother) on years of schooling of children, identifying children-parent pairs if they both residing in the same household. Thus they only provide a point-in-time estimate of mobility based on a sample constructed through co-residence, and do not investigate the evolution of the intergenerational mobility in India.

Finally, Hnatkovskay et.al (2012) used five rounds of National Sample Survey (NSS), covering the period 1983-2005, to analyze intergenerational mobility in occupational choices, educational attainment and wages. They estimate intergenerational elasticities based on 'synthetic' parent-child pairs, wherein they put all household heads into a group called 'parents' and the children/grandchildren into the group 'children'. Specifically, they focus on households with an adult head of household co-residing with at least one adult of lower 
generation (child and/or grandchild), both being in the age-group 16-65. They removed individuals who were enrolled in school at the time of a particular NSS survey round from their analysis. In the next section we highlight the potential sample selection issues in their analysis caused by these selection schemes. They find that the period 1983-2005 has been characterized by a significant convergence of education, occupation distribution, wages and consumption levels of Scheduled Castes/Tribes toward non-Scheduled Castes/Tribes levels.

\section{Data}

We use data from the India Human Development Survey, 2005 (IHDS), a nationally representative survey of households jointly organized by the National Council of Applied Economic Research (NCAER) and the University of Maryland. The IHDS covers 41,554 households in 1503 villages and 971 urban neighborhoods located throughout India. ${ }^{8}$ The survey was conducted between November 2004 and October 2005 and collected wealth of information on education, caste membership, health, employment, marriage, fertility, and geographical location of the household.

There are two distinct advantages of using the IHDS data for an intergenerational education mobility study over the larger and more commonly used household surveys used for the India, such as the National Sample Survey (NSS) and National Family Health Survey (NFHS). First, the IHDS contains additional questions which are not asked in the NSS or

\footnotetext{
${ }^{8}$ The survey covered all the states and union territories of India except Andaman and Nicobar, and Lakshadweep. These two account for less than .05 percent of India's population. The data is publicly available from the Data Sharing for Demographic Research program of the Inter-university Consortium for Political and Social Research (ICPSR).
} 
NFHS. These questions allow us to identify father's education for almost the entire adult male population (in the age group 20-65), co-resident and non co-residents, in our sample. As we discuss in the next section, this will mitigate any downward bias that may entail from sample selection issues associated with identifying parent-child pairs using co-residence condition. Second, the IHDS contain data on actual years of schooling rather than levels of schooling completed which is generally reported in NSS data. ${ }^{9}$ This avoids the discontinuities in schooling distribution as a result of the imputation of years of schooling from the categorical variable containing level of schooling completed.

\subsection{Identification of Father's Educational Attainment}

This section outlines the strategy we used to create a matched father-son data using the IHDS. Specifically, we highlight the additional information in IHDS data that is not available in the NSS or the NFHS that allows us to identify father's schooling for almost every adult male respondent in the age group 20-65.

The first additional variable we use is the "ID of father" in the household roster which helps linking individuals to their fathers directly if the father is living in the household. ${ }^{10,11}$ Note that utilizing this information by default imposes the co-residence condition which we show severely reduces the sample size. Table 1 presents our sample selection process and the loss of observations at each stage. From the last row we observe that using this variable we

\footnotetext{
${ }^{9}$ NFHS also report years of schooling.

${ }^{10}$ Question 2.8 on page 4 of the Household Questionnaire.

${ }^{11}$ In both the NSS and the NFHS, the analogous identification is achieved by utilizing the "relationship to the household head" question in the household roster (see Appendix A).
} 
can only extract father's educational attainment for 34 percent of the male respondents in the age group 20-65.

In contrast to the NSS and the NFHS, the IHDS data has another question regarding the education of household head's father (irrespective of the father living in the household or not). ${ }^{12}$ This helps us to identify fathers' education for household heads who constitute more than 60 percent of the male respondents in the 20-65 age group. Combining this variable with the "ID of father" variable, we are able to identify fathers schooling for about 97 percent of the male respondents in the age group 20-65 (Table 1.B).${ }^{13,14}$ In comparison, Hnatkovskay et al. (2012), who use several rounds of the NSS, were able to identify father's education for less than 15 percent of the male aged 16-65 interviewed in the NSS using their sample selection procedure. ${ }^{15}$

The above issue is of practical as well as theoretical importance as using only co-residence to identify parent's educational attainment may cause severe sample-selection problem. The issue of sample selection and the resulting non-randomness in survey data has been extensively documented in the literature. Franscesconi and Nicoletti (2006) showed that using

\footnotetext{
${ }^{12}$ Question 1.20 on page 3 of the Household Questionnaire.

${ }^{13}$ We also identify fathers' years of education for some of the remaining adult males (who are not the household heads and whose fathers are not identified through co-residence) by exploiting relation to head. A STATA do file used to construct son-father sample is available from the authors.

${ }^{14}$ Note that Maitra and Sharma (2009) also use the IHDS data in their analysis but use co-residence to identify parental educational attainment. As a result, their sample is restricted to only 27.7 and 6.4 percent of total adult male and female sample interviewed in the IHDS. For instance, in Table 4 of their paper, they report a sample size of 5789 and 11515 for males in urban and rural area, although the total adult male (20 and above) sample is 22071 and 40460 in urban and rural areas, respectively. Similarly, they have used only 1886 and 2078 adult female living in urban and rural areas, whereas the total adult female sample is 21790 and 40378 in urban and rural areas, respectively.

${ }^{15}$ In the supplement to their paper, Hnatkovskay et al (2012) report the sample sizes for each round of the NSS. See Table S2: Intergenerational Education Switches: Estimation Results. They report number of observations (son-father pair) of 24119, 28149, 25716, 25994, 27051 in 1983, 1987-88, 1993-94, 1999-00, and 2004-05; while the actual number of males age 16-65 surveyed in these cross-sections are 177,008; 196,412; 173,$182 ; 183,732$; and 188,585 . 
co-residence to identify parent-child pair leads to a downward bias in intergenerational elasticity estimates in the range of 12 to 39 percent. Further, a sample of father-son pair achieved through co-residence may be misleading as it may not be a representative sample of the adult population of interest. For example, we find that in our sample, almost 86 percent of the respondents whose father is identified through co-residence condition are in the 20-35 age group. Hence, co-residence effectively over represents younger adults in a sample, which is expected as these individuals are more likely to be living with their parents. ${ }^{16}$

\subsection{Descriptive Statistics}

Given the objective of the study we focus on the adult population which we define to be the age group 20-65. ${ }^{17}$ Since our survey is from 2005, this implies we have data on individuals born between 1940 and 1985. Hence, we can study the mobility in educational attainment across birth cohorts going as far back as 1940. We conduct our analysis at the all India level, by social groups, and by states. For the all India level and social group level analyses, we divide our sample into nine five year birth cohorts: 1940-45, 1946-50 .... 1976-80, and 1981-85. ${ }^{18}$ In contrast at the state level, driven by sample size and space considerations, we concentrate on two 10 year cohorts: $1951-60$ and 1976-85. ${ }^{19}$

\footnotetext{
${ }^{16}$ In Appendix A we highlight this issue using the 2004-05 round of the NSS.

${ }^{17}$ We chose the lower limit as 20 as a majority of individuals in India finish their college (about 15 years of education) around this age. In our data only 10 (1) percent of age 20-24 (25-29) age group individuals are still in school and haven't completed the maximum of education. Following Behrman et al. (2001) we use an upper age limit of 65 years.

${ }^{18}$ Note that such an aggregation into cohorts introduces a degree of arbitrariness, since one could always use larger or smaller intervals, or space birth cohorts differently. However, aggregation should not bias our trend estimates unless the intervals are chosen with particular results in mind. For present analysis we adopt the five/ten-year age-bands, and did not examine results under alternative aggregation schemes.

${ }^{19}$ We chose to present results for the 1951-60 cohort, as this is the first decade after independence.
} 
The main variable of interest is the son's educational attainment which is measured as years of schooling. In the literature, parents' education is proxy by either father's education, maximum of parents' education, or average of both parents education. In the IHDS we do not have information on mother's education for the whole sample, and hence we proxy parents' educational attainment by father's years of schooling. The sample statistics are presented in Table 2. In the top panel we report summary statistics at the all India level and by social groups whereas in the bottom panel we report these at the state level.

In columns 2 and 3 of the top panel, we present the total sample size and the minimum sample size which is the size of the smallest five-year birth cohort we have for any given cohort. One issue in analyzing education data is the inclusion of individuals who have not completed their education in the sample. This right censoring in the data could reflect delayed completion and/or pursuit of higher education. The main consequence of including individuals who are still in school is that it can potential bias the estimates of intergenerational persistence downward. To shed light on the incidence of right censoring in our data, in columns 4 and 5 of the top panel, we report the shares of adults in our sample who are currently enrolled in school. For those aged 20-24, these shares are on average 10 percent, whereas for the age group 25-29 the shares are less than 1.5 percent. Given the small shares of such individuals in our sample, and the fact that the true value of schooling is most likely to be just a year or two greater than what is observed for the right censored observations, it can be argued that the bias caused by their inclusion should be relatively small.

The last columns in the top panel report the average levels of education for both gener- 
ations for the first and the last five-year birth cohorts. We observe that sons on an average have higher level of education compared to their fathers. Further, between two cohorts, there has been an increase in educational attainment for both generations. This holds for the aggregate as well as across social groups. In terms of social groups, higher Hindu castes are more educated than other groups, and this difference holds for both generations and across cohorts.

In the bottom panel of Table 2 we present the sample sizes for each state in our data as well as average educational attainment for the two generations for two ten year birth cohorts, 1951-60 and 1976-85. ${ }^{20}$ In all states, sons are more educated than fathers and there has been an increase in educational attainment of both generations. However, there is significant variation across states. For instance, Southern states such as Kerala and Tamil Nadu have much higher average educational attainment for sons and fathers when compared to relatively poorer states of Bihar and Orissa. Between two cohorts, at least in terms of average educational attainment, there seems to be some convergence across states.

\section{Conceptual Framework}

In this section we outline the conceptual framework underlying the empirical analysis undertaken in our study. Theories of parental investment in children identify several channels through which family economic circumstances may influence their children's educational at-

\footnotetext{
${ }^{20}$ Due to sample size considerations, we conduct our state level analysis for ten-year birth cohorts rather than five. Also, we exclude Jammu and Kashmir, Delhi, Assam, and the smaller states in the Northeast because the sample sizes in those states for the concerned cohorts fall below 300 father-son pairs.
} 
tainment (Becker and Tomes, 1979, 1986). In these models, decisions regarding child birth and the education of children are determined by the interplay of parental preferences and constraints faced by the family. Such a framework identifies many possible mechanisms that would lead to a direct effect of parental education on child education. First, higher educated parents generally have higher incomes which may positively affect educational attainment of their children by relaxing the family budget constraint. Second, education may increase productivity of the parent in child-enhancing activities which in turn may translate itself into higher educational attainment for the child. In this paper, we are not attempting to uncover the underlying mechanism through which parents' education affects their children's educational attainment. The objective is to simply measure the association between parent and child education, how this association has evolved over time, and whether it is stronger amongst certain groups identified by castes or geographic location.

One objective of this paper is to provide an estimate of the ranking of India, in terms of intergenerational education mobility, amongst other nations. We will compare our estimates for India with the estimates for other nations reported in Hertz et al. (2007). Hence, our empirical methodology closely follows theirs to render our results directly comparable to those reported in Hertz et al. (2007). At the all India level, we estimate the following regression model:

$$
y_{c}^{1}=\beta_{0}+\beta_{1} y_{c}^{0}+\epsilon_{c}^{1}
$$

where $c$ denotes birth cohort, and superscript $i \in[0,1]$ denotes generation $i . y_{c}^{i}$ denotes years 
of schooling of generation $i$ belonging to cohort $c$. We estimate equation (1) above for each of the 5-year birth cohort starting 1940-1985 giving us a total of 9 birth cohorts. The estimated coefficient of $y_{c}^{0}, \widehat{\beta_{1}}$, measures persistence in educational attainment for cohort $c$, where higher values implying greater persistence. Alternatively, $1-\widehat{\beta}_{1}$ is a measure of intergenerational mobility. Comparing $\widehat{\beta_{1}}$ across birth cohorts in our sample will give us a measure of how intergenerational persistence in education has changed over time. Further, by estimating the above model for different castes and states will shed light on whether the pattern in intergenerational mobility varies across different social groups and state boundaries.

In the literature, typically, two measures of intergenerational persistence are used. The first one is $\widehat{\beta}_{1}$ from the above equation. The second measure of persistence, is the intergenerational correlation coefficient, $\rho$, which is given by the following expression:

$$
\rho=\beta_{1} \frac{\sigma_{0}}{\sigma_{1}}
$$

where $\sigma_{i}$ is the standard deviation of educational attainment of generation $i \in[0,1]$.

Hence, the correlation coefficient factors out the cross-sectional dispersion of educational attainment in the two generations, and in that sense is a standardized measure of persistence. In contrast, the regression coefficient is affected by the relative variance of education across generations. If the standard deviation of education is lower in the parent's generation than in the child's, then the regression coefficient exceeds the correlation. Further, changes in the relative standard deviations will cause both measures to evolve differently. For this reason, it is a common practice in the literature to report both measures of persistence. In our 
empirical results we follow this convention and present trends in both regression coefficient correlations across different cohorts in our sample.

The choice of which measure to use is not easy to determine and is primarily a function of what kind of mobility (or lack thereof) one is interested in. If we are only interested in intergenerational mobility across generations, one should use estimated regression coefficients. In contrast, if we are interested in intergenerational mobility, conditional on the overall dispersion of educational attainment for each generation, then one should focus on $\widehat{\rho}$ as a measure of persistence. In our discussion of estimation results (Section 7) we use

the trend in estimated intergenerational elasticities $\left(\widehat{\beta_{1}}\right)$ to suggest the possible role played by various education policy measures undertaken by the state governments and the center government in India.

It is important to note that both measures of intergenerational mobility are simply capturing linear association between the schooling of the father and the son. We do not attempt to uncover the true causal effect of parental education on the child's schooling. It can be argued that the estimated regression coefficient $\left(\widehat{\beta}_{1}\right)$ overstates the true effect, due to the bias caused by omitting confounding socioeconomic factors that may influence education in both generations positively (Hertz et al., 2007).

\section{Empirical Results}

In this section we present our estimation results for intergenerational education elasticities. We first present our results at the all India level, followed by social groups, and last by states. 


\subsection{Regression Results at All India Level}

Table 3 presents the results at the all India level across nine birth cohorts. There are several key findings. First, father's' education has an economically and statistically significant effect on the child's education for each birth cohort. Second, this measure of intergenerational persistence displays a pronounced decline across cohorts, with the estimated coefficient falling from 0.739 for $1940-45$ cohort to 0.508 for the most recent cohort, 1980-85. This provides evidence for increased mobility in educational attainment over time in India.

However, there is no such trend visible in the standardized measure of intergenerational coefficient, $\widehat{\rho}$. This finding is similar to the findings of Hertz et al. (2007). They used data for 43 countries and show that although there is a declining trend in intergenerational persistence based on $\widehat{\beta}_{1}$, there is no trend in $\widehat{\rho}$. They argued that although the standard deviation of child education has remained roughly constant, the dispersion in parental education in their sample was significantly higher for younger cohorts. This will lead to a lower regression coefficient for younger cohorts implying an increase in mobility. However, the correlation coefficient may not reflect such an increase over time.

Following Hertz et al. (2007) we compute the trend in average schooling and in the standard deviations of educational attainment of both generations for our sample and found similar patterns. From Figure 2 we observe that there is an increase in the average level of schooling for both generations. However, the variance of own schooling has decreased whereas that of the parental schooling has increased for younger cohorts. These patterns explain our findings of declining trend in $\widehat{\beta}_{1}$ and lack of trend in $\widehat{\rho}$. Note that this only 
explains why time trend in persistence measured by $\widehat{\beta}_{1}$ is less than that of the trend in $\widehat{\rho}$. But these findings do not explain the sign of the trends underlying these two measures of mobility/persistence. There, negative trend in $\widehat{\beta}_{1}$ implies increases in average educational attainment are driven primarily by increases among children of less educated parents. In contrast, the trend in $\widehat{\rho}$ are much more difficult to explain. For instance, we may see a positive trend in $\widehat{\rho}$ along with a negative trend in $\widehat{\beta_{1}}$, if data becomes more clustered around the regression line.

To compare the level of persistence and rank India in terms of the intergenerational transmission of educational attainment among other countries we follow the approach of Hertz et al. (2007). ${ }^{21}$ We compute a simple average of estimated correlation coefficients across cohorts in our data. We find this average to be 0.52 for India which is above the global average of 0.42 reported by Hertz et al. (2007). Figure 1 presents the ranking of India in terms of intergenerational correlation in educational outcomes. Estimated correlation for cross-country comparison is a more reliable measure for cross-country comparisons as it accounts for changes and differences in standard deviations of educational attainment. We find that India is placed better than other developing countries such as Brazil, Chile, and Indonesia. But it is ranked below than the USA, UK, Malaysia, and Egypt.

\subsection{Regression Results by Social Groups}

Given the historical significance of the caste system in determining economic outcomes in India, it is important to uncover the patterns of intergenerational education mobility that

\footnotetext{
${ }^{21}$ Following similar methodology, Fessler et al. (2012) provide a ranking for Austria.
} 
may be hidden in the estimates at the aggregate level. In this subsection we investigate whether the pattern in intergenerational education mobility differs across social groups. For this purpose we divide our sample into four social groups, namely, Scheduled Caste and Scheduled Tribe (SC/ST), Other Backward Castes (OBC), Muslims, and Higher Hindu Castes $(\mathrm{FC}){ }^{22}$

The regression model we estimate is:

$$
y_{c g}^{1}=\beta_{0}+\beta_{1} y_{c g}^{0}+\epsilon_{c g}^{1}
$$

where $c$ denotes birth cohort, $g$ denotes caste, and superscript $i \in[0,1]$ denotes generation $i$. $y_{c g}^{i}$ denotes years of schooling of generation $i$ belonging to cohort $c$ and social group $g$. We estimate the above equation for each of the four aforementioned social groups and for the nine birth cohorts from 1940-1985.

In Table 4, we present the regression coefficients and estimated correlation by membership to a particular social group. The results are more or less similar to our findings for the all India level that were presented in the previous section. For all four social groups considered, we find a negative trend in $\widehat{\beta_{1}}$. Using $\widehat{\rho}$ as a measure of persistence, there is no discernible trend for FC, SC/ST, and Muslims. However, for OBC we find an increasing trend in $\widehat{\rho}$. To explain these contrasting patterns, for each caste, we compute the trend in average schooling and in the standard deviations of educational attainment of father and son. These results

\footnotetext{
${ }^{22} \mathrm{SC} / \mathrm{ST}$ are historically disadvantaged groups in India, and have enjoyed affirmative policies in education and employment since the independence. OBCs were given reservation in employment in the 1993. Muslims are largest minority religious group in India, and according to GOI (2006), their performance on many economic and educations indicators are comparable to SC/ST.
} 
are presented in Figure 3. We find that for each of the castes, there has been an increase in average years of schooling for both generations. However, in terms of standard deviation of schooling we observe some interesting patterns. First, only for FC there is a secular decline in the standard deviation of own education. For the other three social groups there is no such significant decline across cohorts. Second, in terms of standard deviation of father's educational attainment, all groups witnessed secular increase across cohorts but the OBC witnessed the sharpest increase.

To summarize our findings, based on the estimated regression coefficient for father's education, we find that there is evidence of increased mobility in India, as well as for the four major social groups. As expected, the trends in the correlation coefficient are much harder to discern and only for $\mathrm{OBC}$ we see a positive trend implying lower mobility for this social group in India, conditional on the overall dispersion of educational attainment for each generation

\subsection{Regression Results by State}

Most of the literature addressing intergenerational mobility in economic outcomes in India have emphasized the social dimension and addressed how the caste system in India has affected such mobility. However, another important dimension to this issue concerns the state-wise variation in the intergenerational mobility in economic outcomes. The overall trend in intergenerational mobility in education that we have presented for the aggregate

level and by social groups may mask interesting differences across states for the following 
two reason.

First, the rapid economic growth in recent times has been far from uniformly distributed across state boundaries in India. Chaudhuri and Ravallion (2006) document that, between 1978 and 2004, among the 16 major states, Bihar (including the newly created state of Jharkhand) had the lowest growth rate of 2.2 percent, whereas Karnataka had the highest, 7.2 percent. Such large state-wise variation in growth rates implies increasing regional disparities in India. Asadullah and Yalonetzky (2012) study the state level variation in the degree of inequality of educational opportunities and found that although India has made sizable progress in bringing children from minority social groups to school, there are significant variation in educational achievements at the state level. They document that Southern states experienced lower inequality in educational opportunity when compared to Northern states. Hence, it can be argued that different states may perform differently in terms of providing educational opportunities across generations and hence may have significantly different estimates for intergenerational education elasticities.

Second, till the mid 1970s, the education policy was under the purview of state governments, which in principle could generate significant variation in education policies across states. In order to achieve the national objective of Universal Elementary Education, in 1976, the $42^{\text {nd }}$ amendment to the Indian constitution placed education on the concurrent list. The main implication of this amendment is that the Center government can directly implement any education policy decision in the states. One possible consequence of this change is increased uniformity in education policies across state boundaries, which in turn 
should reduce variation in educational opportunities across states. Hence, one can expect to see smaller cross-state variation in terms of intergenerational education mobility for more recent cohorts.

Against this backdrop, it is of policy interest to investigate whether there are differences across states in terms intergenerational education mobility. As discussed earlier, non-uniform economic growth and inequalities of education opportunity across states may increase the regional variation in intergenerational elasticities. On the other hand, the addition of education on the concurrent list, via greater uniformity in education policies, may reduce the regional variation. In essence, how the state level variation in education mobility has changed across cohorts is an empirical question that we seek to answer in this section.

For the state wise analysis, we exclude all the smaller states in the Northeast, Delhi, Jammu and Kashmir, and Assam due to smaller sample size. ${ }^{23}$ We then estimate the following regression equation :

$$
y_{c s}^{1}=\beta_{0}+\beta_{1} y_{c s}^{0}+\epsilon_{c s}^{1}
$$

where $c$ denotes birth cohort, $s$ denotes state, and superscript $i \in[0,1]$ denotes generation $i$. $y_{c s}^{i}$ denotes years of schooling of generation $i$ belonging to cohort $c$ living in state $s$. We estimate the above equation for each state for two birth cohorts, 1951-60 and 1976-85.

Table 5 presents the results of this exercise. We find that for most states, there is a decline in the estimated regression coefficient of father's education, implying increased mobility. This

\footnotetext{
${ }^{23}$ We only selected those states which has at least a sample size of 300 son-father pairs for each of the 10 year cohort we studied, i.e. 1951-60 and 1976-85 birth cohorts.
} 
finding is consistent with our results at the all India level. Based on standardized persistence we find that out of 15 states, the estimated correlation was higher for ten implying rising persistence based on this measure. There is also substantial cross-state variation with some states faring much better than others.

To discern the regional variation in intergenerational elasticities, we plot the estimated beta coefficient for the two birth cohorts for each state in Figure 4. The horizontal differences in this figure reflect regional variation for the 1951-60 cohort whereas vertical differences reflect this variation for the 1976-85 cohort. We observe that there is substantial variation across states in the estimated beta coefficients for both cohorts. However, this regional variation is much smaller for the more recent cohort implying some convergence among states in terms of intergenerational education mobility. Interestingly this coincides with the timing of the addition of education to the concurrent list that assigned greater role to the center government in affecting education policy at the state level. A full causal analysis of how such a change in policy impacted intergenerational education mobility is beyond the scope of the current study. Our finding is descriptive in nature and points toward one possible explanation underlying the regional patterns presented here.

The solid line in the figure is a 45 degree line. Any point on this line implies no change in the regression coefficient between the two cohorts and hence reflects no change in mobility. The states above the line implies decline in mobility (increase in the persistence) whereas the states below the line implies increase in mobility (decrease in the persistence). The vertical difference between the 45 degree line and symbols for states identifies an improvement in 
mobility over time for that state. Most states, with the exception of Tamil Nadu, fall below the 45 degree line implying increased mobility in educational attainment in these states. However, there is wide variation in the performance of different states in terms of improvements in intergenerational mobility between the cohorts. For instance West Bengal has witnessed very little improvement whereas Madhya Pradesh, Karanataka, and Orissa have experienced significant improvement in mobility between the two cohorts. One plausible explanation for this variation is the state-level differences in education policy. In Section 7 we provide suggestive evidence for this hypothesis by documenting the correlation between per capita state education expenditure and intergenerational mobility.

\section{Education Transition Matrix}

The regression results presented in Section 5 may mask the patterns at the disaggregated level. For instance, one possibility is that sons of less educated fathers are able to attain greater education implying upward mobility. At the same time it is not desirable to have significant regression of education with sons achieving lower education level than fathers. Further, these patterns could vary across social groups. In this section, in order to shed light on these issues, we investigate the extent of education mobility conditional on the location of the father along the education distribution. For this purpose we compute transition matrices, which show how father-son pairs are moving across the distribution of educational attainment. We carry out this analysis at the all India level as well as by social groups for two birth cohorts, 1951-55 and 1981-95. For each of these cohorts we compute $p_{i j}$ where 
where $i$ denotes the education category of the father and $j$ denotes the education category of the son. Thus, $p_{i j}$ is the probability of a father with education category $i$ having a son with education category $j$. Larger values for the diagonal terms, $p_{i i}$, reflect lower mobility. Larger values for off diagonal items, $p_{i j}$, in contrast reflect higher mobility.

Table 6 summarizes the results of this exercise with Panel A reporting transition matrix of the cohort 1951-55, and Panel B document these for the 1981-85 cohort. Each row of the table shows the education of the parent while columns indicate the education category of the child. Thus, the row labeled "Below Primary" suggests that in 1951-55, 50 percent of the adult male children of below primary parents themselves attained below primary education, 18.54 percent finished primary education, 11.89 percent had middle school education, 12.31 percent had secondary education, and 7.14 had post secondary education. Column "size" reports the average share of parents in each education category. Hence, the last cell of the row labeled "Below Primary" suggests that, for the birth cohort 1951-55, roughly 77 percent of the parents had less than primary education.

Table 6 reveals some interesting patterns as regards intergenerational education mobility in India. First, the intergenerational persistence in educational attainment has fallen across birth cohorts, both at the bottom and at the top end of the educational distribution. For instance, for fathers with below primary education, the percentage of sons being in the same education category has fallen from 50.12 for the 1951-55 cohort to 33.18 percent for the 198185 cohort. Second, a large part of this upward intergenerational education mobility was due to sons of fathers with less than primary education beginning to acquire middle school or 
higher education levels. For instance, in 1951-55 31.4 percent of the sons of fathers with less than primary education achieved education level greater than or equal to middle school. In 1981-85, this number increased to 45.1 percent. Finally, there seem to be a decline in persistence at the top end of the distribution, which suggests a regression in sons' educational attainment. For the 1951-55 cohort, 80.2 percent of the sons of fathers with post secondary education remained in that category. For the 1981-85 cohort, this percentage had decreased to 72.7 percent. Finally, we also observe a decline in the share of parents belonging to less than primary education category. Between the two cohorts this share fell from 77.3 percent to 49.5 percent.

Next, we investigate whether this pattern differs across social groups. For this purpose, we look at four social groups, namely, Higher Hindu Castes, Scheduled Caste/Tribes, Other Backward Castes (OBC), and Muslims. In order to avoid the problem of thin cell size, we conduct this analysis for three possible education categories for both generations: less than and equal to primary, middle school, and greater than and equal to secondary. We compute transition matrices for each group for two birth cohorts, 1951-55 and 1981-85 and present the results in Tables 7.A and 7.B.

There are several findings of interest. First, from Table 7.A we find that for both groups there is a decline in the persistence in at the lower end of the education distribution. For the 1951-55 cohort of the higher hindu castes, 45.5 percent of the sons whose fathers had less than equal to primary education remained in that category. For the 1981-85 cohort, this percentage had declined to 33.7 percent. For Scheduled Castes/Tribes, the corresponding 
numbers were 79.2 percent and 53.8 percent. Second, a large part of this mobility was due to sons of fathers with less than and equal to primary education acquiring middle school or higher education levels. For both groups this number increased between two cohorts, from 45.5 percent to 66.3 percent for Higher Hindu Castes and from 29.8 percent to 46.2 percent for Scheduled Castes/Tribes. Finally, at the top end of the education distribution for both groups, especially for Scheduled Castes/Tribes, we observe a significant decline in persistence which suggests a regression in sons' educational attainment. For this group, 84.6 percent of the sons of fathers with greater than equal to secondary education remained in that category for the 1951-55 cohort. For the 1981-85 cohort, this percentage had decreased to 67.8 percent. For Higher Caste Hindus, we do not observe any significant change in this percentage. Similar to our findings at the all India level, for Higher Hindu Castes, the share of parents in the less than primary education category declined from 74.6 to 46.6 percent whereas for Scheduled Castes/Tribes, it fell from 94.6 to 81.3 percent.

From Table 7.B we observe slightly different patterns for Other Backward Castes and Muslims. Similar to our findings for Higher Caste Hindus, and Scheduled Castes/Tribes, both of these groups experienced a rise in mobility at the lower end of the educational distribution. However, at the top end of this distribution, here both groups experience an increase in persistence. For Other Backward Castes, 82.9 percent of the sons of fathers with greater than equal to secondary education remained in that category for the 1951-55 cohort. For the 1981-85 cohort, this percentage had increased to 84.9 percent. The corresponding numbers were 70.3 percent and 71.6 percent for Muslims. Finally, for Other Backward 
Castes, the share of parents in the less than primary education category declined from 93.5

to 65.8 percent whereas for Muslims, it fell from 88.7 to 71.8 percent.

24

Overall, we find that both at the all India level as well as by social groups, there is strong evidence for upward mobility in education at the lower end of the educational distribution. At the top end of the distribution, we find increased persistence for Other Backward Castes and Muslims and lower persistence for Scheduled Castes/Tribes. These results uncover interesting patterns in mobility across social groups along the education distribution that were not discernible from our regression analysis, and hence complements our findings in Sections 5.1 and 5.2.

\section{Discussion}

The results presented in this paper provide a useful description of how different cohorts have faired in terms of educational attainment, conditional on their fathers' education. Based on the estimated intergenerational elasticity, the transmission of educational attainment from father to son has decreased significantly across birth cohorts in last 45 years. This trend

\footnotetext{
${ }^{24}$ In a recent paper, Hnatkovskay et al. (2012) used the NSS data and presented transition matrix for education mobility for year 1983 and 2004-05 based on cross-section data. For both rounds they document an unusually high level of regression of education attainments of children with almost 50 (63 for SC/ST) percent of the children of highly educated parents getting less education than their parents (see Table 5, Hnatkovskay et al., 2012). Since our analysis is done by cohorts, the results presented here are not directly comparable to those presented in Hnatkovskay et al. However, we believe that one plausible explanation for their findings is their sample selection procedure that rests on co-residence sample and also an age cut off of 16-65 for both son and father. In Appendix A, we illustrate how imposing co-residence leads to an over representation of younger adults in the NSS sample and may severely affect mobility estimates based on the coresident sample. In addition to the coresident, they also drop the enrolled students from their sample. As, the proportion of enrolled persons is quite high at lower ages (e.g., in age 16-20), they lose a significant proportion of persons who would been counted in the higher cells.
} 
holds true across social groups and geographic boundaries, with significant regional variation in intergenerational mobility. However, based on the estimated correlation between fatherson educational attainment, no such trend is visible. As discussed earlier, the discrepancy between the two measures is due to the evolution of the dispersion in educational attainment of the two generations. Choosing between the two depends on the perception one has about the appropriate measure of differences in economic outcomes. In this section we use the rise in mobility as measured using intergenerational elasticity estimates presented in the paper and attempt to correlate this rise with various education policy measure undertaken by the Indian government.

The issue of how changes in policy is correlated with changes in educational attainment of individuals has been extensively addressed in the literature (Black and Deveraux, 2011). Hertz et al. (2007) provide a detailed survey of studies that document correlation between changes in policy environment and intergenerational educational mobility for various countries. One important stylized fact reported in this literature is that greater government expenditure on primary schooling is negatively associated with educational persistence. Given that we find declining cohort trend in intergenerational education elasticity for India, one plausible explanation for this finding can stem from the changes over time in the educational policy environment in India. From 1950 onwards the Government of India (GOI) has undertaken several policy measures to promote Universal Elementary Education (UEE) in an attempt to eliminate all forms of discrimination based on caste, community and gender. In recent decades, India has made significant progress in increasing enrollment and school 
completion (Kingdon, 2007). The policy efforts are reflected in the Five year plans as well as specific policy measures undertaken to promote education. Table B in the appendix B provide a brief chronology of the education policy in India. In light of these policy measures, it can be hypothesized that our finding of rising mobility in educational attainment across cohorts to some degree reflects the success of these policies in equalizing educational opportunities over time and across regional boundaries.

One of the important findings we report in this paper relates to the regional variation in education mobility across generations. We present some evidence for correlation between this regional variation in mobility and state-level education policy. Under the constitution of India constitution, till 1976, education was the responsibility of the state. In 1976 education was added to the concurrent list and since then the Center government has played an increasing role in expanding education and achieving greater uniformity in education policy across regions. This has often been supplemented by efforts from state governments who have undertaken considerable educational investments in recent decades. ${ }^{25}$ Asadullah and Yalonetzky (2012) emphasize the importance of state-level differences in policies and institutions in generating inequality in educational opportunity for a number of reasons.

For our purpose, one such factor is the difference across states in terms of overall spending on education. One possibility for observed regional variation in educational mobility could be differing state education expenditure. ${ }^{26}$ Although not causal, an association between

\footnotetext{
${ }^{25}$ Some examples of state sponsored education schemes include Education Guarantee Scheme in Madhya Pradesh, Basic Education Program in Uttar Pradesh, Lok Jumbish and Shiksha Karmi programs in Rajasthan, and Balyam Program of Andhra Pradesh (Asadullah and Yalonetzky, 2012).

${ }^{26}$ Note that we are not arguing that education spending by state will suffice to equalize opportunities. As Asadullah and Yalonetzky (2012) points out, educational policies implemented in states can play a crucial role in determining a state's success in equalizing educational opportunities.
} 
state education spending and the estimated patterns in intergenerational mobility presented here will be of policy interest. In order to investigate this connection, we follow Asadullah and Yalonetzky (2012) and use Besley, Burgess, and Esteve-Volart (2007) ranking of Indian states in terms of state education expenditure per capita for the period 1958-2000. In Figure 5, we plot this measure of policy performance against estimated mobility measure for each state $\left(1-\widehat{\beta_{1}}\right)$ for the birth cohort $1951-60$ and $1976-85$, respectively. We observe that states that are ranked higher in terms of per capita education spending on an average have higher intergenerational mobility in educational attainment. The direction of this correlation is consistent with the findings reported in Hertz et al. (2007). Further, we find that this association is stronger for the birth cohort of 1976-85, a cohort that would have been in school during most of 1980s and 1990s. This is expected given the lags involved in policy implementation and effects. Our policy measure is based on average state expenditure for the period 1958-2000. Given this timing, one would expect to find stronger association for later cohorts than for the earlier cohort of 1951-1960, as a significant fraction of the older cohort may have completed their schooling before being impacted by state level spending that was initiated between 1958-2000. The evidence presented here although not causal, seem to suggest strong positive association between intergenerational educational mobility and public spending on education. Hence, it can be argued that part of the cross-state variation in intergenerational mobility could be generated by regional variation in public spending in education. 


\section{Conclusion}

This paper investigates the extent of intergenerational mobility in India. Using a nationally representative survey of households, IHDS, we create a unique father-son matched data that does not require the co-residence condition and hence is not subject to the sample selection issues that typically plague most studies for India. Following the methodology of Hertz et al. (2007) we find that for the period 1940-85, there has been an increase in mobility in educational attainment in India. The average intergenerational correlation for the Indian economy is 0.52 which is higher than the average global correlation of 0.42 reported by Hertz et al. (2007). We also find that there has been an improvement in mobility across social groups, especially at the lower end of the education distribution. This provides suggestive evidence that the universal primary education program adopted by the Indian government since 1970s has impacted the availability of education opportunities for all social groups. Finally, we provide evidence for differential pattens in intergenerational education mobility across states, with some states faring much worse than others. One possible explanation for this finding is the state-wide differences in educational policies. Although not causal, we provide suggestive evidence for a strong association between state level spending on education and intergenerational mobility. 


\section{References}

[1] Asadullah, M. Niaz and Yalonetzky, Gaston. 2012. "Inequality of Educational Opportunity in India: Changes Over Time and Across States." World Development, 40(6): 11511163.

[2] Becker, G. S. and N. Tomes. (1979). "An Equilibrium Theory of the Distribution of Income and Intergenerational Mobility", Journal of Political Economy 87(6): 1153-1189.

[3] Becker, G. S. and N. Tomes. (1986). "Human Capital and the Rise and Fall of Families," Journal of Labor Economics, 4(3): S1-S39.

[4] Behrman, Jere, Alejandro Gaviria, and Miguel Szkely. (2001). "Intergenerational mobility in Latin America." Economia, 2(1): 1-44.

[5] Besley, T., Burgess, R., and Esteve-Volart, B. (2007). "The policy origins of poverty and growth in India." In Tim Besley, and Louise Cord (Eds.), Delivering on the promise of pro-poor growth. London: Palgrave Macmillan and the World Bank.

[6] Black, S., and P. Devereux. (2011). "Recent Developments in Intergenerational Mobility." Handbook of Labor Economics, 4(B), Ch-16, 1487- 1541.

[7] Chaudhuri, Shubham and Ravallion, Martin. "Partially Awakened Giants: Uneven Growth in China and India." Dancing with Giants: China, India and the Global Economy. Ed. L. Alan Winters and Shahid Yusuf. Washington DC: World Bank, 2006. 
[8] Daude, Christian. (2011). "Ascendance by Descendants? On Intergenerational Education Mobility in Latin America." OECD Development Centre Working Papers, Paper No. 297.

[9] Fessler, P., Mooslechner, P., and Schurz, M. (2012), "Intergenerational Transmission of Educational Attainment in Austria," Empirica, 39,65-86.

[10] Government of India. (2006). "Social, Economic and Education Status of the Muslim community of India." New Delhi.

[11] Hertz, Tom, Jayasunderay, Tamara, Pirainoz, Patrizio, Selcuk, Sibel, Smithyy, Nicole, and Verashchagina, Alina. 2007. "The Inheritance of Educational Inequality: International Comparisons and Fifty-Year Trends." The B.E. Journal of Economic Analysis and Policy (Advances), 7 (2), 1-46.

[12] Hnatkovskay, V., Lahiri, A., and Paul, S., B. (2012), "Breaking the Caste Barrier: Intergenerational Mobility in India." Unpublished manuscript, University of British Columbia.

[13] Jalan, J. and Murgai, R. (2008), "Intergenerational Mobility in Education in India," Paper Presented at the Indian Statistical Institute, Delhi.

[14] Kingdon, G. (2007). "The progress of school education in India." Oxford Review of Economic Policy, 23(2): 168195.

[15] Maitra, P. and Sharma, A. (2009), "Parents and Children: Education Across Generations in India, Unpublished manuscript, Department of Economics, Monash University. 
[16] Munshi, K. and M. Rosenzweig. (2009), "Why is Mobility in India so Low? Social Insurance, Inequality, and Growth." Unpublished Manuscript.

[17] Munshi, K. and M. Rosenzweig. (2006), "Traditional Institutions meet the Modern World: Caste, Gender, and Schooling Choice in a Globalizing Economy." The American Economic Review, 96(4): 1225-1252.

[18] Ray Jhilam and Majumder, Rajarshi. (2010), "Educational and occupational mobility across generations in India: social and regional dimensions." Unpublished Manuscript. 
Table 1: Sample Selection

Number of Observations Treatment

Males aged 20-65 in IHDS-2005

58,194

Years of schooling missing

306

Dropped

Male aged 20-65 with schooling information

Individual is household head's father, no information about head father's father in data

Males aged 20-65 who can be potentially be matched with father information in data

(Percentage of Male aged 20-65 with school information)

Number of individuals that could not be matched with father

57,888

591

Dropped

Number of Individuals matched with father in data

Father identified but missing years of schooling

57,297

$(99.0 \%)$

$532 \quad$ Dropped

Final Sample: Son-father pairs with education information

56.765

$724 \quad$ Dropped

(Percentage of Male aged 20-65 who can be potentially matched)

55480

$(96.8 \%)$

Son-Father pairs with education information using Co-residence

19,490

(Percentage of Male aged 20-65 who can be potentially matched)

$(34.0 \%)$ 
Table 2: Descriptive Statistics

\begin{tabular}{|c|c|c|c|c|c|c|c|c|}
\hline \multirow{3}{*}{ Socio-group } & \multicolumn{2}{|c|}{ Sample Size } & \multicolumn{2}{|c|}{ Share enrolled* } & \multicolumn{4}{|c|}{ Average Years of education } \\
\hline & Total & $\underline{\text { Min }}$ & Age 20-24 & Age 25-29 & \multicolumn{2}{|c|}{$\underline{\text { Father }}$} & \multicolumn{2}{|c|}{$\underline{\text { Son }}$} \\
\hline & & & & & $\underline{1940-45}$ & $\underline{1981-85}$ & $\underline{1940-45}$ & $\underline{1981-85}$ \\
\hline $\begin{array}{l}\text { All } \\
\text { Higher Hindu castes (FC) } \\
\text { Other Backward Castes (OBC) } \\
\text { Scheduled Castes/ Tribes (SC/ST) } \\
\text { Muslim }\end{array}$ & $\begin{array}{l}55450 \\
13,160 \\
18,946 \\
10753 \\
6,409\end{array}$ & $\begin{array}{l}3419 \\
1,836 \\
2,583 \\
1,333 \\
794\end{array}$ & $\begin{array}{c}10.3 \\
14.9 \\
9.3 \\
8.2 \\
10.6\end{array}$ & $\begin{array}{l}1 \\
1.5 \\
0.6 \\
1.1 \\
0.7\end{array}$ & $\begin{array}{c}2 \\
3.8 \\
1.5 \\
0.8 \\
2\end{array}$ & $\begin{array}{c}4.9 \\
7.3 \\
5 \\
3.1 \\
4.3\end{array}$ & $\begin{array}{c}4.3 \\
7.3 \\
4 \\
2.2 \\
3.8\end{array}$ & $\begin{array}{c}8.3 \\
10.3 \\
8.6 \\
7 \\
6.9\end{array}$ \\
\hline Muslim & & & & & \multicolumn{4}{|c|}{ Average Years of education } \\
\hline \multirow[t]{2}{*}{$\underline{\text { State }}$} & \multicolumn{2}{|c|}{$\underline{\text { Sample Size }}$} & & & \multicolumn{2}{|c|}{$\underline{\text { Son }}$} & \multicolumn{2}{|c|}{$\underline{\text { Father }}$} \\
\hline & $\underline{1951-60}$ & $\underline{1976-85}$ & & & $\underline{1951-60}$ & $\underline{1976-85}$ & $\underline{1951-60}$ & $\underline{1976-85}$ \\
\hline $\begin{array}{l}\text { Andhra Pradesh } \\
\text { Bihar } \\
\text { Gujarat } \\
\text { Haryana } \\
\text { Himachal Pradesh } \\
\text { Karnataka } \\
\text { Kerala } \\
\text { Madhya Pradesh } \\
\text { Maharashtra } \\
\text { Orissa } \\
\text { Punjab } \\
\text { Rajasthan } \\
\text { Tamil Nadu } \\
\text { Uttar Pradesh } \\
\text { West Bengal }\end{array}$ & $\begin{array}{l}472 \\
602 \\
507 \\
395 \\
337 \\
979 \\
443 \\
957 \\
827 \\
488 \\
430 \\
597 \\
549 \\
900 \\
581\end{array}$ & $\begin{array}{c}878 \\
1,040 \\
794 \\
871 \\
586 \\
1,731 \\
578 \\
1,894 \\
1,501 \\
790 \\
803 \\
1,157 \\
736 \\
1,722 \\
874\end{array}$ & & & $\begin{array}{c}4.2 \\
5 \\
6.2 \\
6 \\
7.1 \\
5.4 \\
8.2 \\
5.1 \\
6.8 \\
5.2 \\
6.7 \\
5.1 \\
6.5 \\
5.7 \\
6.4\end{array}$ & $\begin{array}{c}7.6 \\
7.1 \\
7.9 \\
8.6 \\
9.8 \\
8.1 \\
10.5 \\
7.2 \\
9.8 \\
7.7 \\
9 \\
7.1 \\
9.3 \\
7.6 \\
6.8\end{array}$ & $\begin{array}{l}1.4 \\
2 \\
2.5 \\
2 \\
1.7 \\
2.1 \\
4.1 \\
1.8 \\
2.6 \\
1.8 \\
2.5 \\
1.4 \\
2.1 \\
2 \\
3.8\end{array}$ & $\begin{array}{c}3.1 \\
4.1 \\
5 \\
4.3 \\
5 \\
4.2 \\
6.1 \\
4 \\
5.5 \\
3.6 \\
5.2 \\
3.7 \\
5 \\
4.5 \\
4.8\end{array}$ \\
\hline
\end{tabular}

i) The total sample size refers adult male persons aged 20-65 in 2004-05, born between 1940 and 1985 .

ii) Minimum sample size refers to the size of the smallest five-year birth cohort we have for any given cohort.

iii) Father refers to fathers of the persons belonging to different cohorts.

iv) * Enrolled and have less than the highest achievable (15 years) education years.

v) Time interval refers to son's birth cohort. For example, 1951-55 represents cohort of sons born during this period.

6) Jammu and Kashmir, Delhi, Assam, and North East excluded the sample size was below 300. 
Table 3: Intergenerational Mobility in Education, All India

Dependent Variable: Son's years of schooling

\section{Son's Birth Cohort}

$\begin{array}{lllllllll}1940-45 & 1946-50 & 1951-55 & 1956-60 & 1961-65 & 1966-70 & 1971-75 & 1976-80 & 1981-85\end{array}$

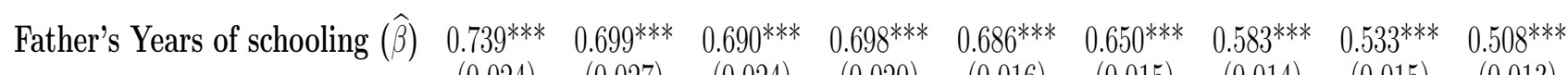

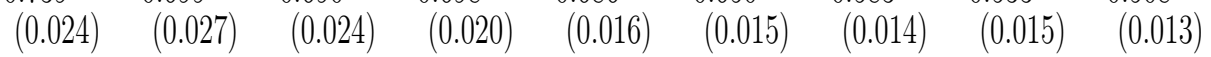

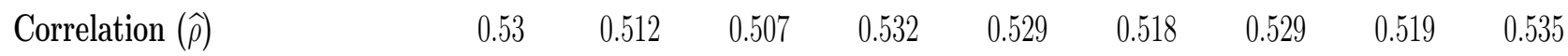

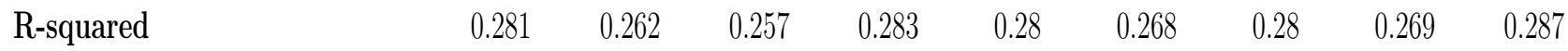

\begin{tabular}{llllllllll} 
Observations & 4005 & 3419 & 4453 & 5566 & 6018 & 7008 & 7286 & 8341 & 9354 \\
\hline \hline
\end{tabular}

${ }^{* * *} p>0.01 ; * * p>0.05 ;{ }^{*} p>0.10$.

Robust standard errors are in parentheses. 
Table 4: Intergenerational Mobility in Education by Social Groups

Dependent variable: Son's years of schooling

$\underline{\text { Son's Birth Cohort }}$

$\begin{array}{lllllllll}1940-45 & 1946-50 & 1951-55 & 1956-60 & 1961-65 & 1966-70 & 1971-75 & 1976-80 & 1981-85\end{array}$

\begin{tabular}{|c|c|c|c|c|c|c|c|c|c|}
\hline \multirow[b]{2}{*}{ Father's years of schooling $(\widehat{\beta})$} & \multicolumn{9}{|c|}{ Higher Hindu Castes } \\
\hline & $\begin{array}{c}0.582^{* * *} \\
(0.033)\end{array}$ & $\begin{array}{c}0.596^{* * *} \\
(0.034)\end{array}$ & $\begin{array}{c}0.495^{* * *} \\
(0.038)\end{array}$ & $\begin{array}{c}0.560^{* * *} * \\
(0.028)\end{array}$ & $\begin{array}{c}0.510^{* * *} \\
(0.025)\end{array}$ & $\begin{array}{c}0.510^{* * *} \\
(0.023)\end{array}$ & $\begin{array}{c}0.455^{* * *} \\
(0.025)\end{array}$ & $\begin{array}{c}0.436^{* * *} \\
(0.035)\end{array}$ & $\begin{array}{c}0.406^{* * *} \\
(0.021)\end{array}$ \\
\hline Correlation $(\hat{\rho})$ & 0.524 & 0.552 & 0.484 & 0.534 & 0.521 & 0.526 & 0.518 & 0.525 & 0.52 \\
\hline \multirow[t]{2}{*}{$\begin{array}{l}\text { Observations } \\
\text { R-squared }\end{array}$} & $\begin{array}{c}967 \\
0.275\end{array}$ & $\begin{array}{c}869 \\
0.305\end{array}$ & $\begin{array}{l}1,140 \\
0.235\end{array}$ & $\begin{array}{l}1,370 \\
0.285\end{array}$ & $\begin{array}{l}1,474 \\
0.271\end{array}$ & $\begin{array}{l}1,634 \\
0.276\end{array}$ & $\begin{array}{l}1,783 \\
0.268\end{array}$ & $\begin{array}{l}1,905 \\
0.275\end{array}$ & $\begin{array}{l}2,018 \\
0.271\end{array}$ \\
\hline & \multicolumn{9}{|c|}{ Other Backward Castes } \\
\hline Father's years of schooling $(\widehat{\beta})$ & $\begin{array}{c}0.608^{* * *} \\
(0.065)\end{array}$ & $\begin{array}{c}0.547^{* * *} \\
(0.070)\end{array}$ & $\begin{array}{c}0.643^{* * *} \\
(0.053)\end{array}$ & $\begin{array}{c}0.589^{* * *} \\
(0.044)\end{array}$ & $\begin{array}{c}0.645^{* * *} \\
(0.033)\end{array}$ & $\begin{array}{c}0.621^{* * *} \\
(0.030)\end{array}$ & $\begin{array}{c}0.559 * * * \\
(0.026)\end{array}$ & $\begin{array}{c}0.477^{* * *} \\
(0.025)\end{array}$ & $\begin{array}{c}0.487^{* * *} \\
(0.028)\end{array}$ \\
\hline Correlation $(\hat{\rho})$ & 0.387 & 0.367 & 0.412 & 0.432 & 0.466 & 0.476 & 0.487 & 0.455 & 0.516 \\
\hline \multirow[t]{2}{*}{$\begin{array}{l}\text { Observations } \\
\text { R-squared }\end{array}$} & $\begin{array}{l}1,411 \\
0.15\end{array}$ & $\begin{array}{l}1,172 \\
0.135\end{array}$ & $\begin{array}{l}1,519 \\
0.17\end{array}$ & $\begin{array}{l}1,920 \\
0.187\end{array}$ & $\begin{array}{l}2,027 \\
0.217\end{array}$ & $\begin{array}{l}2,363 \\
0.226\end{array}$ & $\begin{array}{l}2,530 \\
0.237\end{array}$ & $\begin{array}{l}2,890 \\
0.207\end{array}$ & $\begin{array}{l}3,114 \\
0.267\end{array}$ \\
\hline & \multicolumn{9}{|c|}{ Scheduled Castes/Tribes } \\
\hline Father's years of schooling $(\hat{\beta})$ & $\begin{array}{c}0.680^{* * *} \\
(0.081)\end{array}$ & $\begin{array}{c}0.702^{* * *} \\
(0.060)\end{array}$ & $\begin{array}{c}0.760^{* * *} \\
(0.038)\end{array}$ & $\begin{array}{c}0.705^{* * *} \\
(0.045)\end{array}$ & $\begin{array}{c}0.685^{* * *} \\
(0.043)\end{array}$ & $\begin{array}{c}0.649^{* * *} \\
(0.041)\end{array}$ & $\begin{array}{c}0.595^{* * *} \\
(0.030)\end{array}$ & $\begin{array}{c}0.525^{* * *} \\
(0.027)\end{array}$ & $\begin{array}{c}0.467^{* * *} \\
(0.027)\end{array}$ \\
\hline Correlation $(\hat{\rho})$ & 0.398 & 0.403 & 0.457 & 0.427 & 0.449 & 0.387 & 0.44 & 0.438 & 0.424 \\
\hline $\begin{array}{l}\text { Observations } \\
\text { R-squared }\end{array}$ & $\begin{array}{l}1,014 \\
0.158\end{array}$ & $\begin{array}{c}915 \\
0.162\end{array}$ & $\begin{array}{l}1,166 \\
0.209\end{array}$ & $\begin{array}{l}1,458 \\
0.182\end{array}$ & $\begin{array}{l}1,667 \\
0.201\end{array}$ & $\begin{array}{l}1,950 \\
0.15\end{array}$ & $\begin{array}{l}1,922 \\
0.194\end{array}$ & $\begin{array}{l}2,298 \\
0.192\end{array}$ & $\begin{array}{l}2,622 \\
0.179\end{array}$ \\
\hline & \multicolumn{9}{|c|}{$\underline{\text { Muslims }}$} \\
\hline Father's years of schooling $(\widehat{\beta})$ & $\begin{array}{c}0.718^{* * * *} \\
(0.065)\end{array}$ & $\begin{array}{c}0.626^{* * *} \\
(0.088)\end{array}$ & $\begin{array}{c}0.682^{* * *} \\
(0.060)\end{array}$ & $\begin{array}{c}0.742^{* * *} \\
(0.047)\end{array}$ & $\begin{array}{c}0.622^{* * *} \\
(0.051)\end{array}$ & $\begin{array}{c}0.588^{* * *} \\
(0.046)\end{array}$ & $\begin{array}{c}0.589^{* * *} \\
(0.042)\end{array}$ & $\begin{array}{c}0.615^{* * *} \\
(0.034)\end{array}$ & $\begin{array}{c}0.571^{* * *} \\
(0.026)\end{array}$ \\
\hline Correlation $(\hat{\rho})$ & 0.516 & 0.459 & 0.525 & 0.567 & 0.466 & 0.469 & 0.504 & 0.556 & 0.555 \\
\hline $\begin{array}{l}\text { Observations } \\
\text { R-squared }\end{array}$ & $\begin{array}{c}442 \\
0.266\end{array}$ & $\begin{array}{c}352 \\
0.211\end{array}$ & $\begin{array}{l}462 \\
0.275\end{array}$ & $\begin{array}{c}580 \\
0.322\end{array}$ & $\begin{array}{c}628 \\
0.217\end{array}$ & $\begin{array}{l}814 \\
0.22\end{array}$ & $\begin{array}{c}802 \\
0.254\end{array}$ & $\begin{array}{l}1,013 \\
0.309\end{array}$ & $\begin{array}{l}1,316 \\
0.308\end{array}$ \\
\hline
\end{tabular}

${ }^{* * *} \mathrm{p}>0.01 ; * \mathrm{*} p>0.05 ;{ }^{*} \mathrm{p}>0.10$.

Robust standard errors are in parentheses. 
Table 5: Intergenerational Mobility, State Level

$\underline{\text { Son's Birth Cohort: 1951-60 }}$ Son's Birth Cohort: 1976-85

\begin{tabular}{|c|c|c|c|c|}
\hline State & beta-Coefficient & Correlation & beta-Coefficient & Correlation \\
\hline Andhra Pradesh & 0.710 & 0.466 & 0.553 & 0.476 \\
\hline Bihar & $\begin{array}{c}0.709 \\
(0.047)\end{array}$ & 0.524 & $\begin{array}{c}(0.035) \\
0.573 \\
(0.025)\end{array}$ & 0.575 \\
\hline Gujarat & $\begin{array}{c}0.717 \\
(0.053)\end{array}$ & 0.518 & $\begin{array}{c}0.478 \\
(0.028)\end{array}$ & 0.512 \\
\hline Haryana & $\begin{array}{c}0.651 \\
(0.053)\end{array}$ & 0.529 & $\begin{array}{c}0.425 \\
(0.027)\end{array}$ & 0.472 \\
\hline Himachal Pradesh & $\begin{array}{c}0.539 \\
(0.067)\end{array}$ & 0.401 & $\begin{array}{c}0.330 \\
(0.028)\end{array}$ & 0.440 \\
\hline Karnataka & $\begin{array}{c}0.810 \\
(0.039)\end{array}$ & 0.556 & $\begin{array}{c}0.497 \\
(0.022)\end{array}$ & 0.483 \\
\hline Kerala & $\begin{array}{c}0.447 \\
(0.042)\end{array}$ & 0.449 & $\begin{array}{l}0.378 \\
(0.03)\end{array}$ & 0.467 \\
\hline Madhya Pradesh & $\begin{array}{c}0.856 \\
(0.040)\end{array}$ & 0.568 & $\begin{array}{c}0.511 \\
(0.020)\end{array}$ & 0.509 \\
\hline Maharashtra & $\begin{array}{c}0.620 \\
(0.038)\end{array}$ & 0.491 & $\begin{array}{c}0.367 \\
(0.019)\end{array}$ & 0.440 \\
\hline Orissa & $\begin{array}{c}0.802 \\
(0.063)\end{array}$ & 0.498 & $\begin{array}{c}0.496 \\
(0.034)\end{array}$ & 0.457 \\
\hline Punjab & $\begin{array}{c}0.579 \\
(0.057)\end{array}$ & 0.438 & $\begin{array}{c}0.443 \\
(0.024)\end{array}$ & 0.542 \\
\hline Rajasthan & $\begin{array}{c}0.775 \\
(0.059)\end{array}$ & 0.474 & $\begin{array}{c}0.515 \\
(0.026)\end{array}$ & 0.501 \\
\hline Tamil Nadu & $\begin{array}{l}0.421 \\
(0.05)\end{array}$ & 0.338 & $\begin{array}{c}0.471 \\
(0.029)\end{array}$ & 0.516 \\
\hline Uttar Pradesh & $\begin{array}{c}0.751 \\
(0.041)\end{array}$ & 0.526 & $\begin{array}{c}0.529 \\
(0.020)\end{array}$ & 0.533 \\
\hline West Bengal & $\begin{array}{c}0.696 \\
(0.037)\end{array}$ & 0.613 & $\begin{array}{c}0.673 \\
(0.025)\end{array}$ & 0.670 \\
\hline
\end{tabular}

i) Jammu and Kashmir, Delhi, Assam, and North East excluded because sample size was below 300.

ii) Robust standard errors are in parentheses. 
Table 6: Intergenerational Transitional Probabilities, All India

Panel A- Son's Birth Cohort: 1951-55

Son's Education:

$<$ Primary Primary Middle School Secondary Post Secondary size

Father's Education:

\begin{tabular}{lllllll} 
S Primary & 0.501 & 0.185 & 0.119 & 0.123 & 0.071 & 0.773 \\
Primary & 0.099 & 0.234 & 0.207 & 0.215 & 0.245 & 0.112 \\
Middle & 0.046 & 0.052 & 0.293 & 0.308 & 0.301 & 0.044 \\
Secondary & 0.029 & 0.035 & 0.114 & 0.376 & 0.446 & 0.041 \\
Post Secondary & 0.017 & 0.030 & 0.070 & 0.081 & 0.802 & 0.030 \\
\hline
\end{tabular}

Panel B- Son's Birth Cohort: 1981-85

Son's Education:

$<$ Primary Primary Middle School Secondary Post Secondary size

Father's Education:

\begin{tabular}{lllllll}
$<$ Primary & 0.332 & 0.217 & 0.224 & 0.117 & 0.110 & 0.495 \\
Primary & 0.105 & 0.198 & 0.293 & 0.173 & 0.231 & 0.173 \\
Middle & 0.053 & 0.105 & 0.321 & 0.192 & 0.330 & 0.116 \\
Secondary & 0.024 & 0.048 & 0.167 & 0.238 & 0.523 & 0.125 \\
Post Secondary & 0.008 & 0.022 & 0.078 & 0.165 & 0.727 & 0.092 \\
\hline \hline
\end{tabular}

i) Each cell $i j$ represents the average probability (for a given cohort) of father with education level $i$ having a son with education attainment level $j$.

ii) Column titled "size" reports the fraction of parents in each education category. 


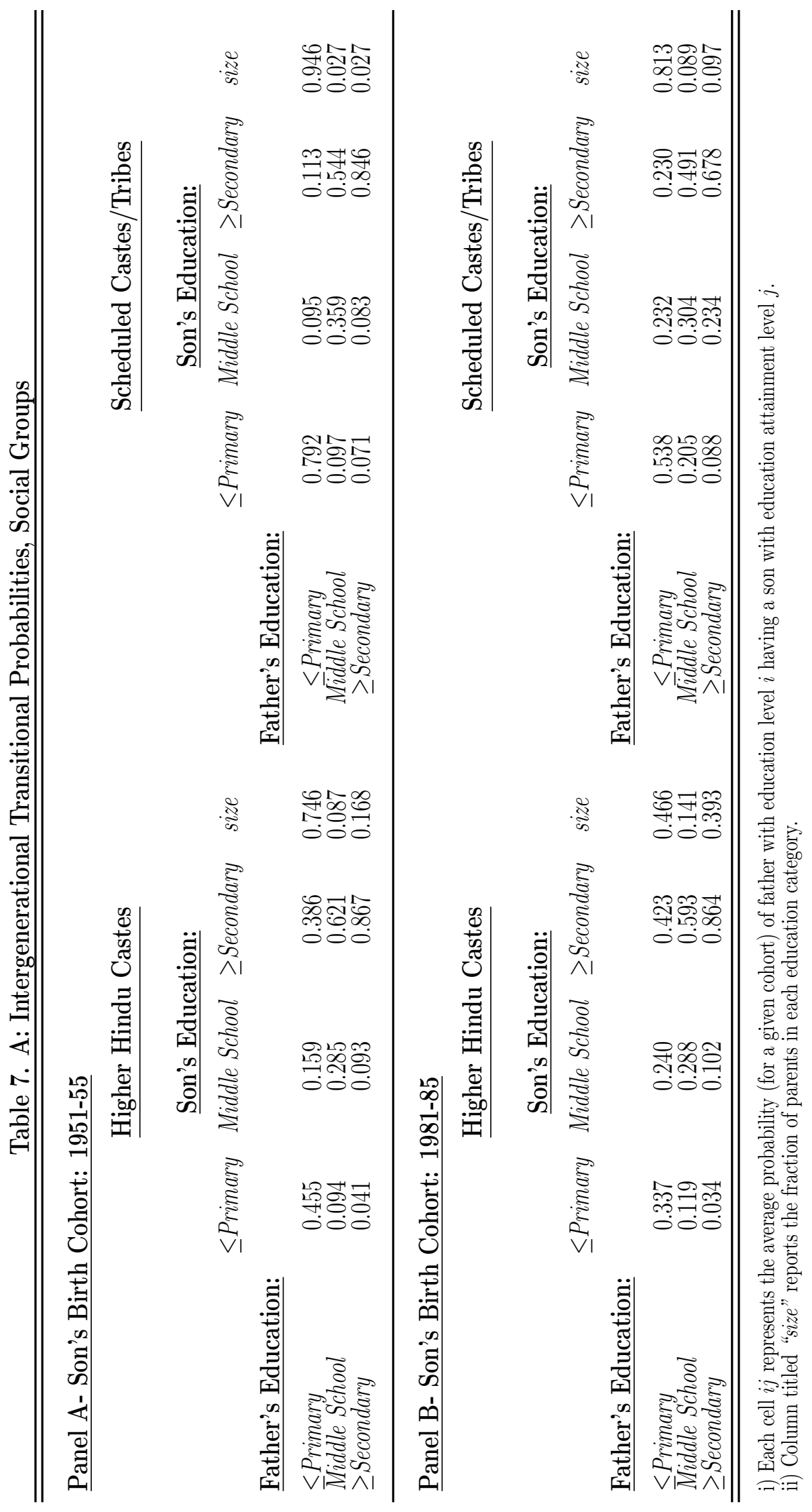




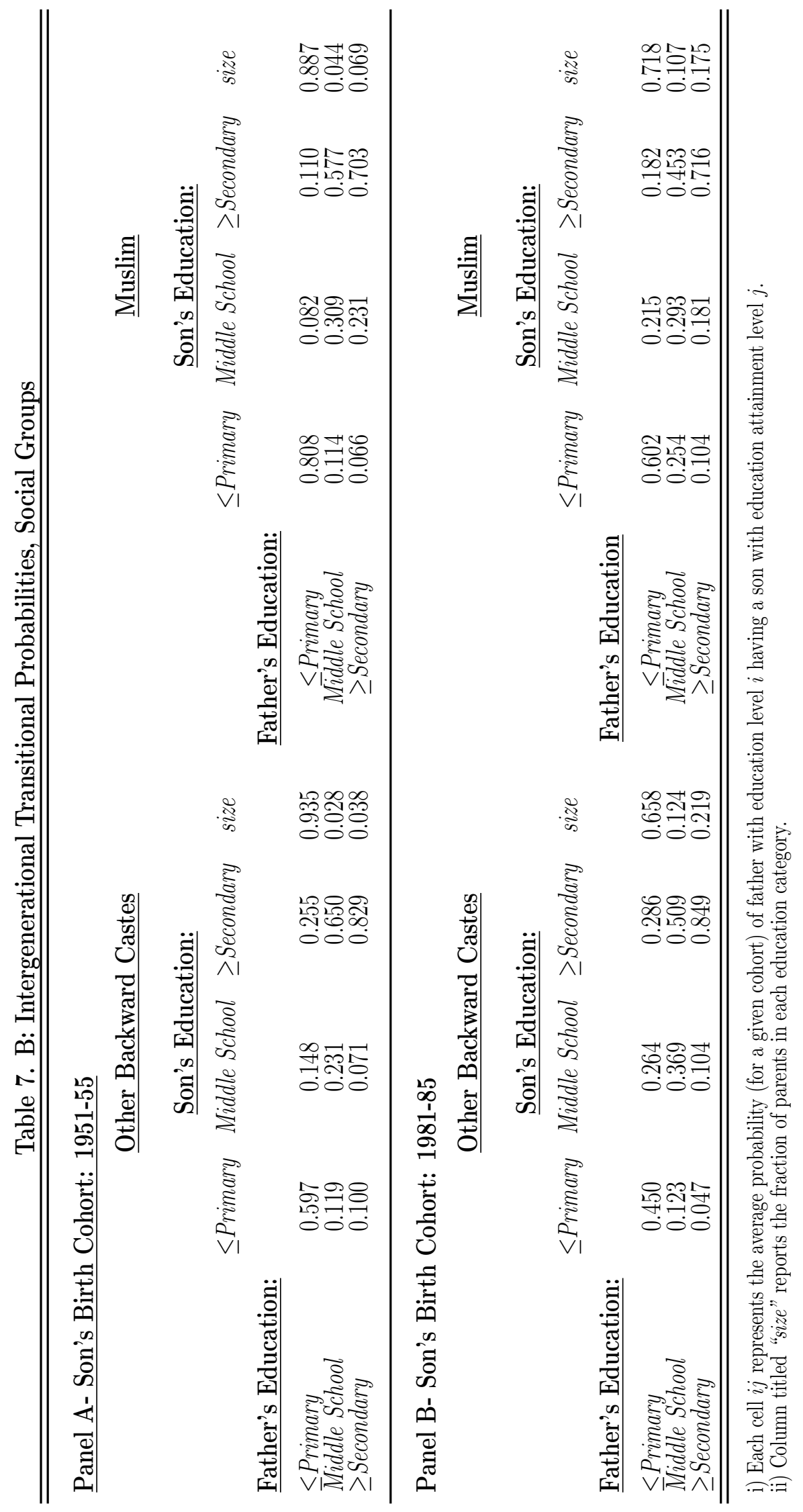


Figure 1: Ranking India in terms of Intergenerational Mobility

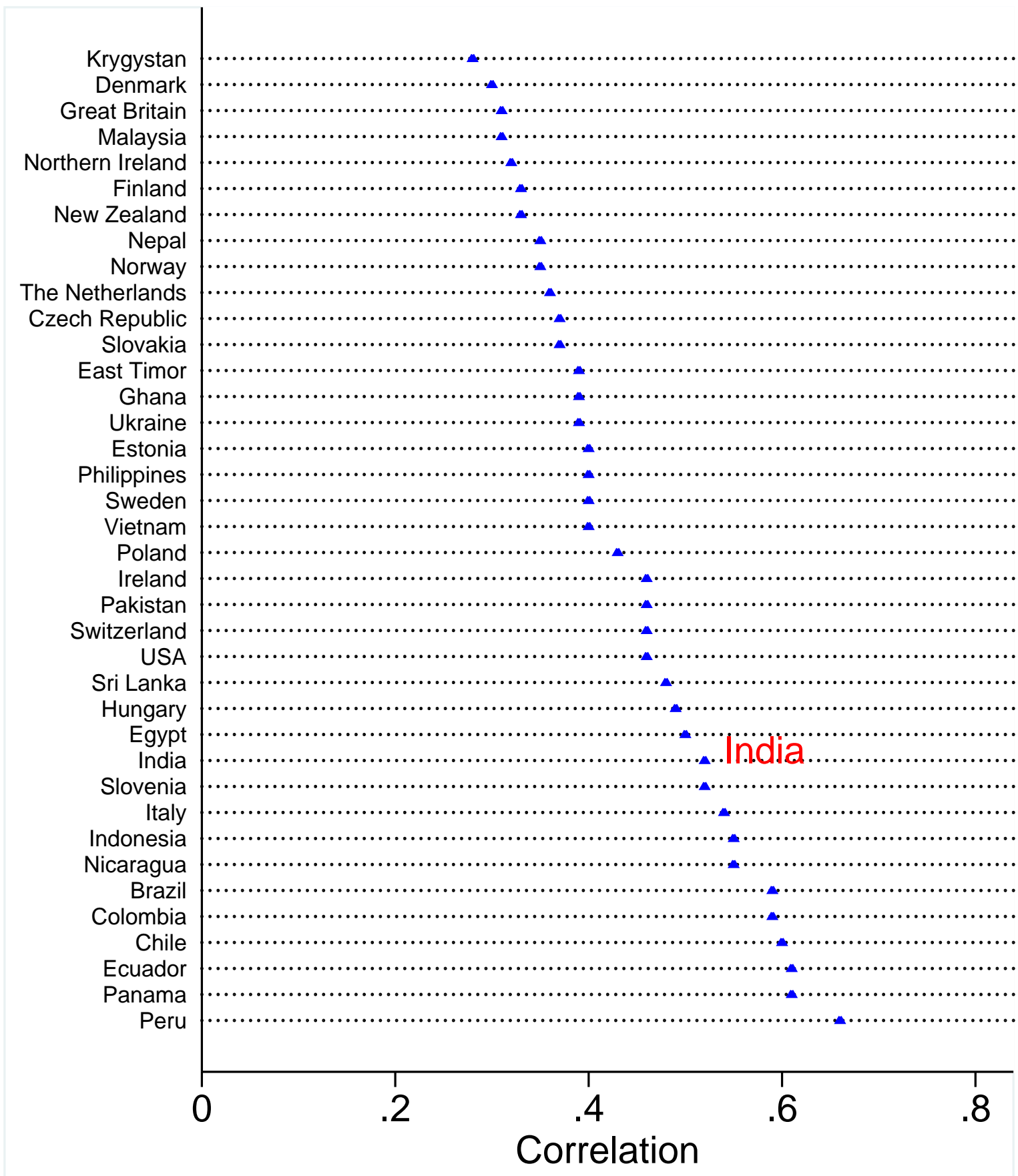

Note: Estimate for India are from Authors' calculation. Estimates for other nations are from Hertz et al. (2008), Table 2. 
Figure 2: Average and Standard Deviation of years of schooling, ALL India
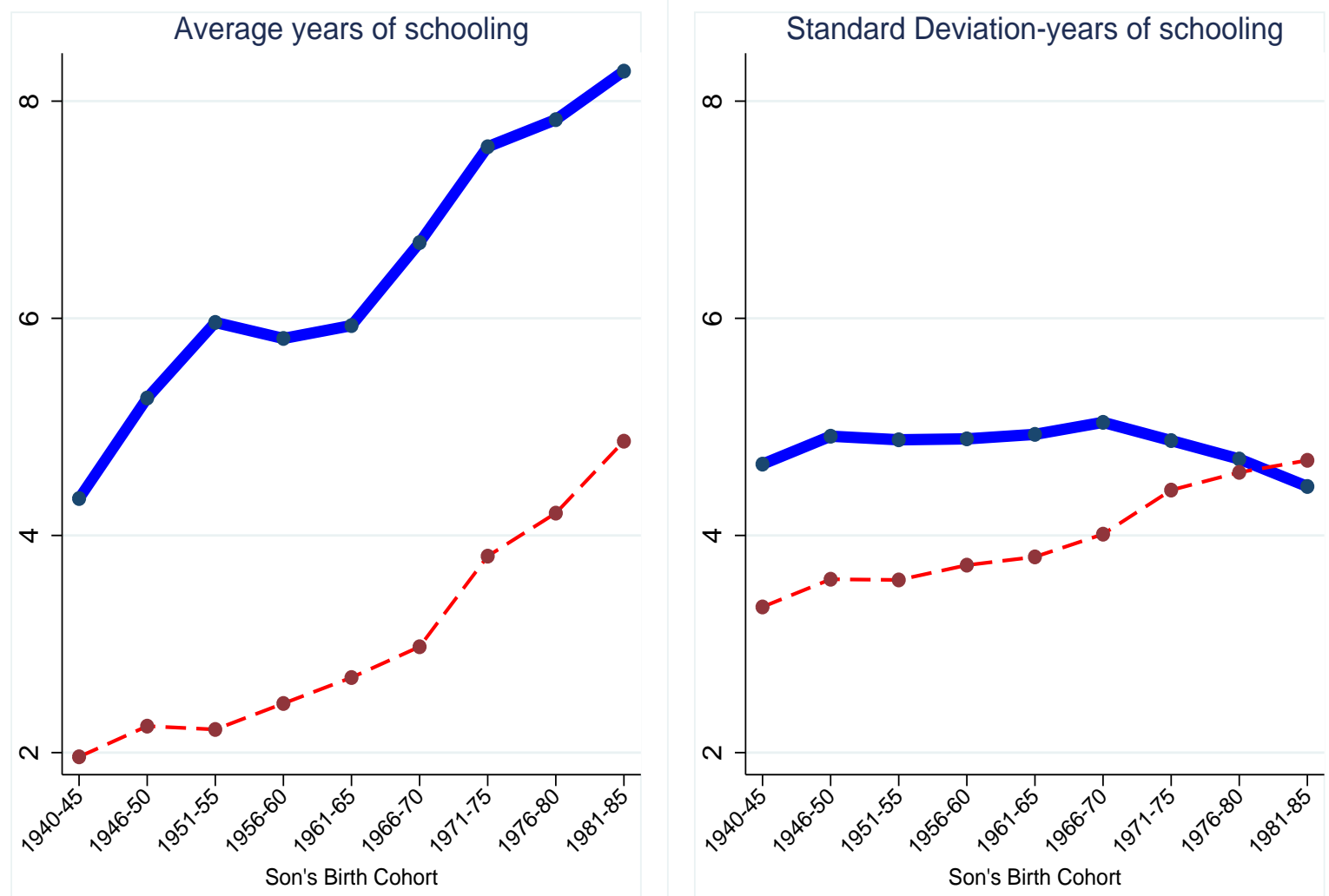

$$
\text { Son - - - - Father }
$$


Figure 3: Average and Standard Deviation of years of schooling by Social Groups

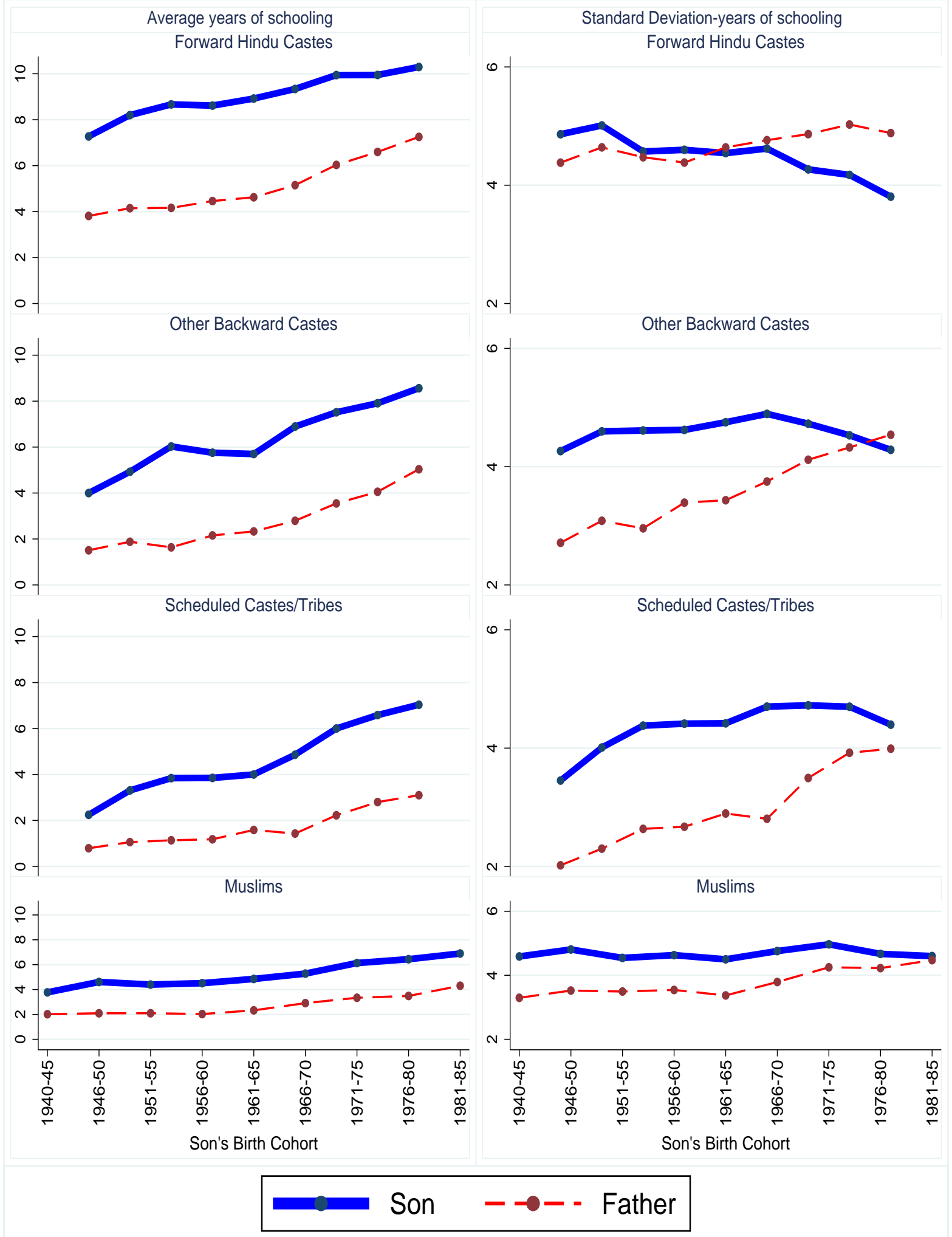


Figure 4: Intergenerational Mobility, State Level

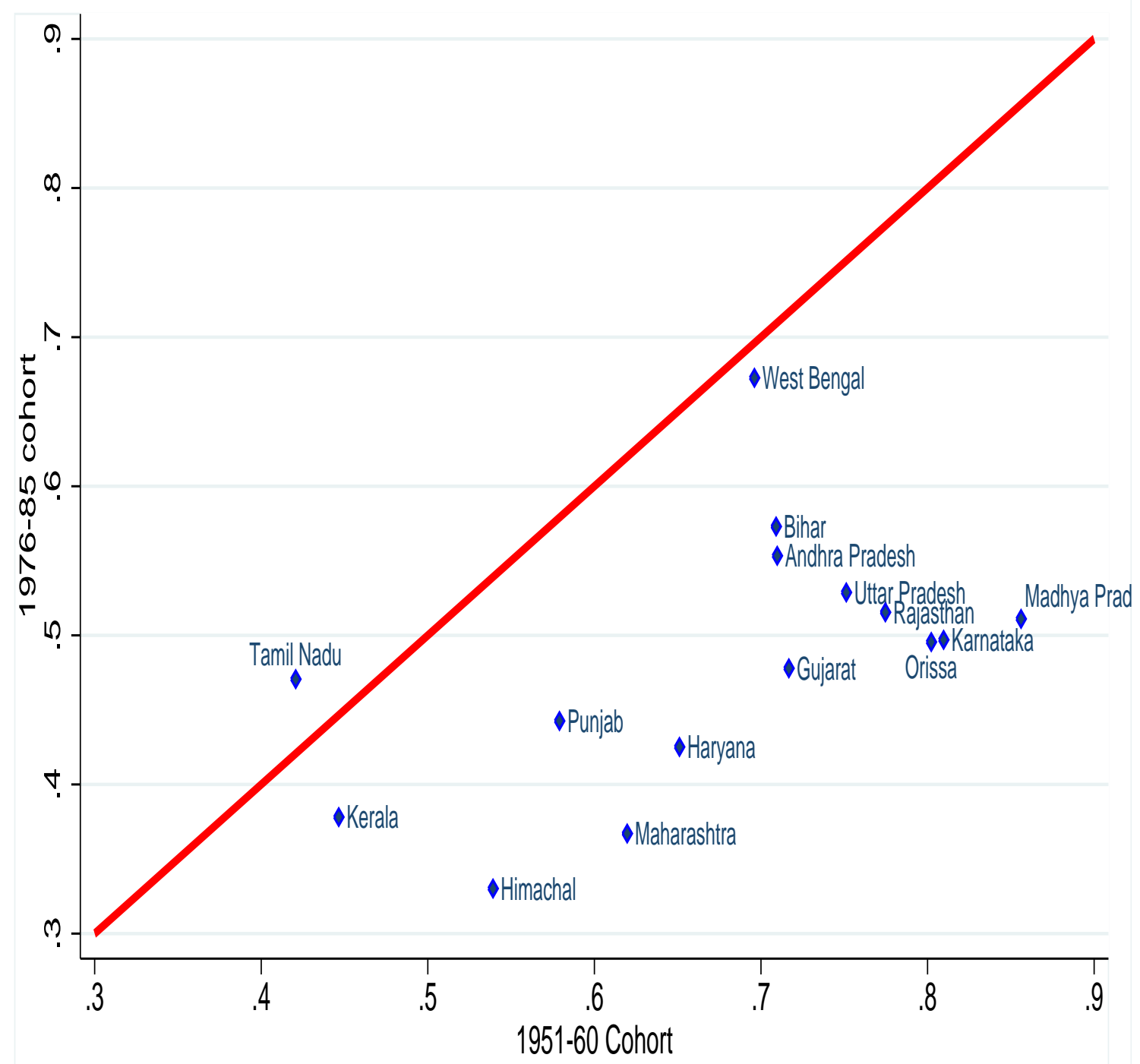

Note: Jammu and Kashmir, Delhi, Assam, and Northeast excluded because of smaller sample sizes. See text for details. 
Figure 5: Intergenerational Mobility and Public Educational Spending, State Level

5a) Birth Cohort: 1951-60

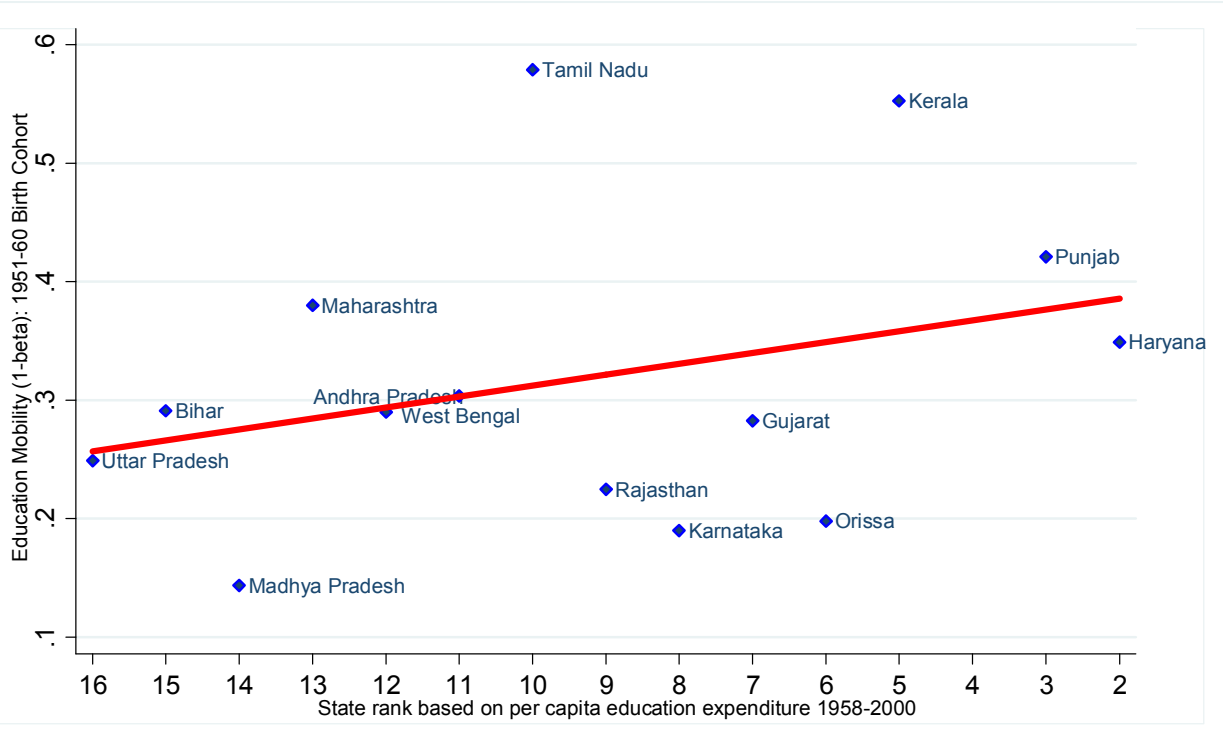

5b) Birth Cohort: 1976-85

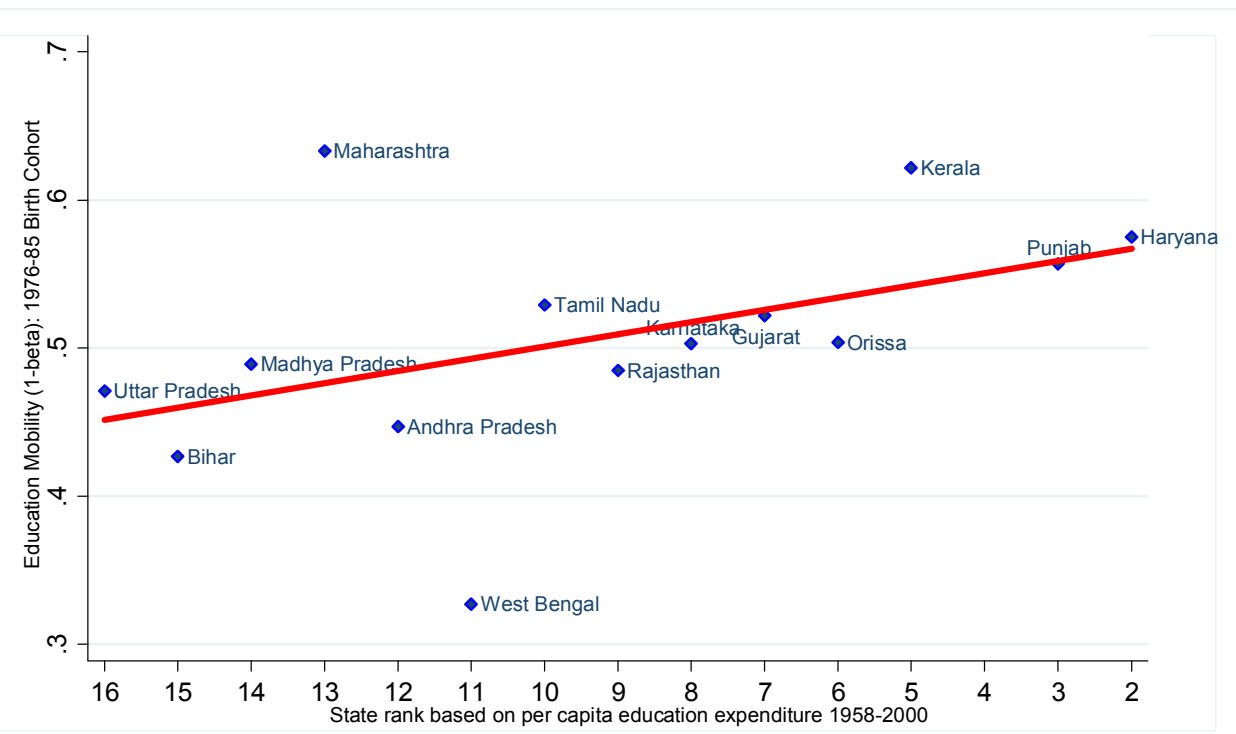

Note: Jammu and Kashmir was ranked 1 in terms of per capita education spending. However, our analysis excludes this state due to smaller sample size. 


\section{Appendix A: Co-residence condition and Sample Selection in the NSS}

In this section, we illustrate the sample selection issues that may arise due to the identification of father-son pairs based on co-residence. Using the $61^{\text {st }}$ round of the NSS (2004-05), we first show that the sample of adult males that can be matched with their father's information using the co-residence condition disproportionately represents younger individuals. Then, we also show that even one concentrates on relatively younger cohorts (i.e. restricting the analysis to only younger cohorts, such as 20-30 age group), the persons for whom father's information is identified may not be a random subsample of the concerned age group.

Table A.1: Distribution of population aged 20-65 based on the relationship to head, NSS 2004-05

\begin{tabular}{llcc}
\hline \hline \multirow{2}{*}{ Relation to the Head (Code) } & \multirow{2}{*}{ Relation to the Head } & \multicolumn{2}{c}{ Sample Size } \\
\cline { 3 - 4 } & & Male & Female \\
1 & Self & 101,053 & 12,284 \\
2 & Spouse of head & 338 & 96,721 \\
3 & Married child & 25,954 & 2,720 \\
4 & Spouse of married child & 881 & 25,823 \\
5 & Unmarried child & 24,927 & 10,845 \\
6 & Grandchild & 1,111 & 662 \\
7 & Father/ mother/ father-in-law/ mother-in-law & 1,296 & 7,556 \\
8 & Brother/ sister/ brother-in-law/ sister-in-law/ other relatives & 7,314 & 5,860 \\
9 & Servants/ employees/ other non-relatives & 564 & 203 \\
\hline \multirow{2}{*}{ Total } & & 163,438 & 162,674 \\
\hline \hline
\end{tabular}

Source: NSS 61st Round Employment and Unemployment Survey, 2004-05

In the NSS data set (similarly, in the NFHS), parents identification is achieved through imposition of co-resident condition and exploiting the "relationship to head" information. Table A.1 provide the information on the various types of relationship captured in this vari- 
able and the corresponding sample sizes in the 2004-05 round of the NSS. ${ }^{27}$ As is evident from the sample sizes reported in Table A.1, using co-residence to identify father's information would lead to severe loss of observations. This is because almost 62 percent of adult male sample consist of household's head whose father information is not available. One can potentially identify fathers' for only those male persons in age 20-65 who has reported relationship to head as married/unmarried child (50,881 individuals or 31 percent of the entire adult male population). Hence males in age 20-65 who reported as child of head can be matched to head if head is male or with spouse (if alive and co-resident) of head if head is female. Out of 50,991 persons who reported as child of head, 44,228 live in male headed households, while 6,653 live in female headed households. However, 6508 female headed households do not have spouse of head living in household. Hence, through co-resident, we could identify father's education only for 44,373 males in age 20-65, which is merely 27 percent of the total males in age 20-65.

Figure A.1 presents the age distribution of male in the age group 20-65 for the entire sample and for the co-resident sample (matched with their father using the co-residence condition). As we observe from this figure, there are significant difference in the age distribution of the two samples. Specifically, a large majority of the co-resident sample is concentrated in the 20-30 age group (roughly 80 percent). Hence, using co-residence we have an oversample of younger adults which is expected as these individuals are more likely to be residing with

\footnotetext{
${ }^{27}$ In the NFHS (2005-06), "relation to head" has following categories: 1-self, 2-wife or husband, 3-son/daughter, 4-son/daughter-in-law, 5-grandchildren, 6-parents, 7-parents-in-law, 8-brother/sister, 9brother/sister-in-law, 10-niece/nephew, 11-other relatives, 12-adopted/foster/step child, 13-domestics servants, 14-other non relatives.
} 
Figure A.1: Age distribution of males in the age group 20-65, NSS 2004-05
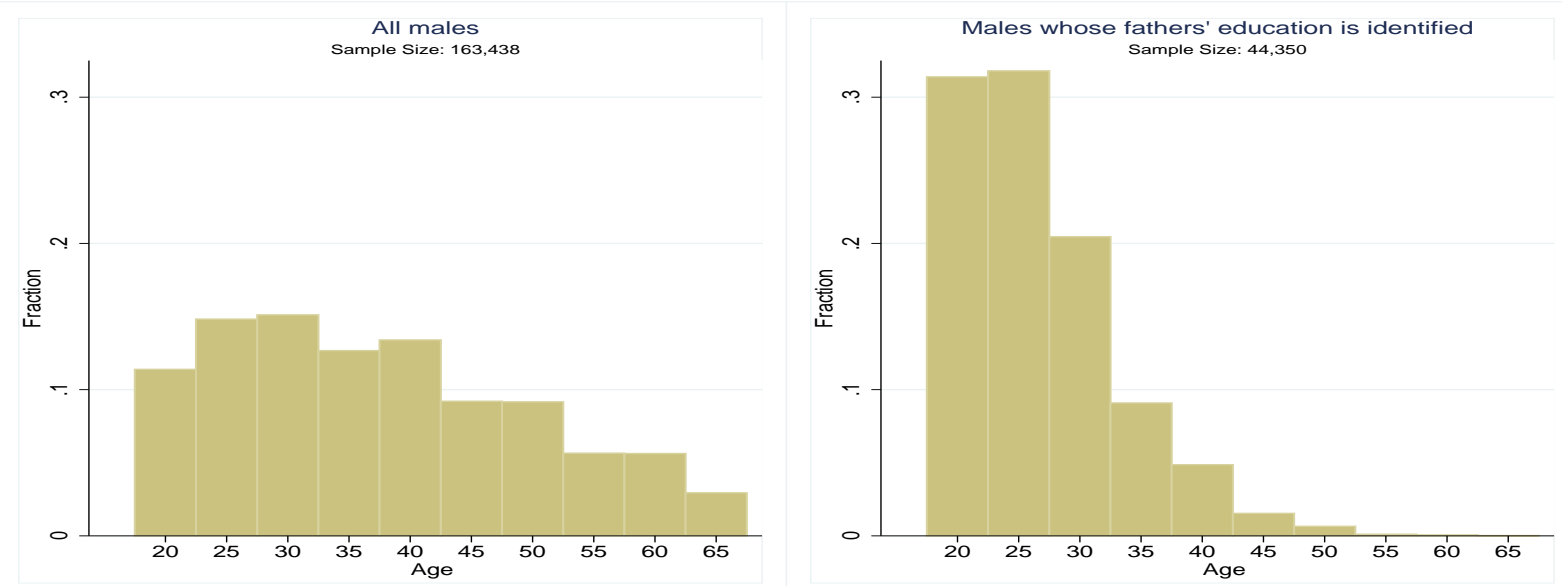

Note: Survey weights are used to get the age distribution.

their parents.

In addition to having a non-representative sample of the adult male population, the father's education information identified in each age group may not be randomly distributed across observations. In Figure A.2, we plot the proportion in each age group (male) whose father education is identified using the co-resident sample from the 2004-05 NSS round. Again, we find that in the co-resident sample, although the percentage of individuals whose father's education can be identified are much higher for the younger age groups, it remains a non random sub sample of that particular age group. As a result, not only the estimates (cross-section estimates) of intergenerational mobility based on the father-son pair identified through co-residence would be biased, but also the bias will not be eliminated even if one concentrate on only younger age groups. 
Figure A.2: Proportion in each age group (male) whose father education is identified in the NSS, 2004-05

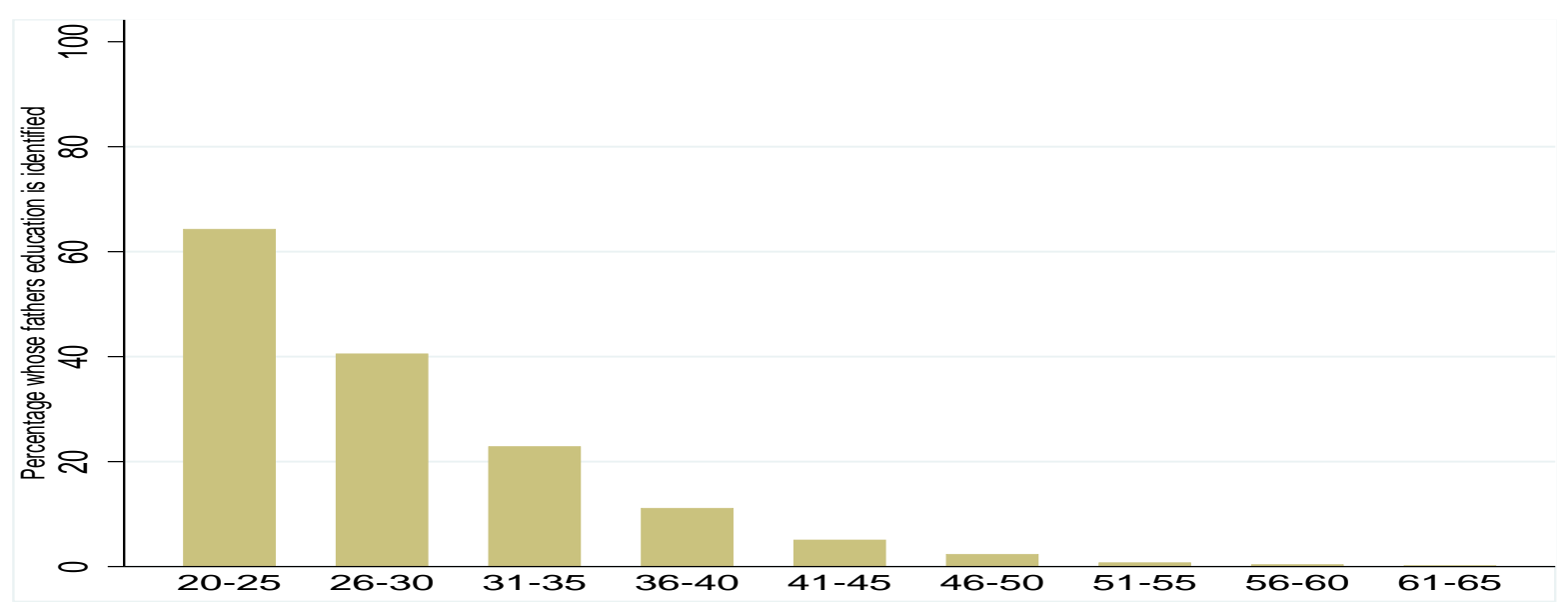

Note: Survey weights are used to calculate the proportions. 


\section{Appendix B: Evolution of Education Policy in India}

Table B: Education Policy in India 1951-2005

\begin{tabular}{|c|c|c|}
\hline$\underline{\text { Period }}$ & Policy Framework & Policy Measures and Programmes \\
\hline $1951-68$ & $\begin{array}{l}\text { Constitution } \\
\text { of India }\end{array}$ & $\begin{array}{l}\text { Expansion of the formal schooling system. State governments } \\
\text { shoulder the responsibility for primary education. }\end{array}$ \\
\hline $1968-86$ & $\begin{array}{l}\text { National Policy on } \\
\text { Education, } 1968\end{array}$ & $\begin{array}{l}\text { 1976: Education shifted to the Concurrent list thereby } \\
\text { giving the GOI and state governments equal } \\
\text { responsibility for promoting and managing education. } \\
\text { 1980s: Non-Formal Education introduced to supplement } \\
\text { formal schooling, thereby increasing Central investment } \\
\text { in primary schooling. }\end{array}$ \\
\hline 1986-92 & $\begin{array}{l}\text { National Policy on } \\
\text { Education, } \\
\text { Jomtien Conference } \\
\text { for Education for All, } \\
\text { followed by EFA } \\
\text { projects most of } \\
\text { them with foreign } \\
\text { aid }\end{array}$ & $\begin{array}{l}\text { Andhra Pradesh Primary Education Project, early } 1980 \\
1986 \text { (British ODA) Environmental Education, } 1986 \\
\text { (Domestic Resources) Rajasthan Shiksha Karmi Project, } \\
1987 \text { (Sida) Total Literacy Campaign, } 1988 \\
\text { (Domestic resources) Mahila Samakhya in Karnataka, } \\
\text { UP and Gujarat, } 1989 \text { (Dutch Government) Bihar } \\
\text { Education Project, } 1991 \text { (UNICEF) Rajasthan Lok Jumbish, } 1992 \text { (Sida) } \\
\text { UP Basic Education Project, } 1992 \text { (World Bank) }\end{array}$ \\
\hline $1992-2002$ & $\begin{array}{l}\text { Revised National } \\
\text { Policy on Education } \\
\text { Mid-day meal, 1995, } \\
\text { Supreme Court Order } \\
\text { on Mid-day meal, } 2001\end{array}$ & $\begin{array}{l}\text { District Primary Education Programme (DPEP), } 1993 \\
\text { National Programme of Nutritional Support to Primary Education } \\
\text { (Mid Day Meal), 1997, Sarva Shiksha Abhiyan, } 2001\end{array}$ \\
\hline 2002 onwards & $\begin{array}{l}\text { Free and compulsory } \\
\text { education bill, } 2004 \\
\text { Revised Mid-day meal } \\
\text { Programme in } 2004\end{array}$ & $\begin{array}{l}\text { Free and Compulsory Education made fundamental right of children } \\
\text { in the age group 6-14 } \\
\text { Universal Mid-day meal across primary schools in the country }\end{array}$ \\
\hline
\end{tabular}

Source: Ensuring Universal Access To Health and Education In India, November 2007. 